TRABAJOS DE PREHISTORIA

69, N. ${ }^{\circ}$ 2, julio-diciembre 2012, pp. 310-331, ISSN: 0082-5638

doi: $10.3989 /$ tp. 2012.12094

\title{
Fíbulas de codo "tipo Huelva" en la Península Ibérica: nuevos datos y comentarios historiográficos
}

\author{
Elbow Fibulae of Huelva Type in the Iberian Peninsula: New Data and Historiographic \\ Comments
}

Javier Carrasco Rus (*)

Juan Antonio Pachón Romero (*)

Ignacio Montero-Ruiz (**)

Jesús Gámiz Jiménez $(*)$

\section{RESUMEN}

Una nueva fíbula de codo "tipo Huelva" localizada en la región gallega será nuestro objeto de discusión en este trabajo. Para su estudio, analizaremos otras piezas similares localizadas en el entorno del Cerro de los Infantes (Pinos Puente, Granada) que, junto a las ya conocidas, conforman uno de los grupos fibulares más importantes de la Península Ibérica. Discutiremos su tipología y cronología, así como su relación con otros tipos similares del ámbito mediterráneo, comprobándose nuevamente su carácter autóctono.

\begin{abstract}
In this paper, a new find of an elbow fibula, the socalled Huelva type located in the Galicia region will be discussed. In order to carry out the study of this piece, we have analyzed other fibulae documented at Cerro de los Infantes (Pinos Puente, Granada, Spain), which make up one of the most important fibulae assemblages of the Iberian Peninsula. Several aspects, such us their typology and their chronology, as well as their relationship with other types of fibulae from the Mediterranean area, confirm the native origin of this new fibula.
\end{abstract}

Palabras clave: Fíbula de codo "tipo Huelva"; Bronce Final; Aleaciones binarias; Taller metalúrgico; Ría de Huelva; Península Ibérica.

(*) Dpto. de Prehistoria y Arqueología, Facultad de Filosofía y Letras, Universidad de Granada. Campus de Cartuja, 18071 Granada. Correos e.: jcrus@ugr.es, japr@arrakis.es, gamizjimenez@gmail.com

(**) Instituto de Historia. Centro de Ciencias Humanas y Sociales-CSIC. C/ Albasanz, 26-28. 28037-Madrid.

Correo e.: ignacio.montero@cchs.csic.es

Recibido: 6-VII-2011; aceptado: 8-XI-2011.
Key words: Elbow fibulae known as Huelva type; Late Bronze Age; Binary alloys; Metallurgical workshop; Estuary of Huelva; Iberian Peninsula.

\section{INTRODUCCIÓN}

Al inicio de la década de 1980, las excavaciones en los yacimientos protohistóricos de Cerro de la Mora y Cerro de la Miel (Moraleda de Zafayona, Granada) proporcionaron ciertos hallazgos metálicos (espada de lengua de carpa y fíbula de codo) que podían paralelizarse formalmente con los depósitos broncíneos de la Ría de Huelva. Ambos lugares, pero básicamente el Cerro de la Mora, arrojaron un conjunto masivo de fíbulas de codo y evidencias de restos de fundición y de estructuras relacionadas con actividades productivas metalúrgicas, que muestran cómo el sitio tuvo un papel económico destacado a fines de la Edad del Bronce. De todo ese conjunto metálico, la única fíbula asociable al característico "tipo Huelva" procedía de La Miel. Su contextualización, junto con la espada y una fecha de C14, facilitó subir la cronología de estos elementos hasta momentos discrepantes respecto de la ortodoxia cronológica aceptada hasta entonces (Almagro Basch 1957, 1957-58, 1966; AlmagroGorbea 1977; Almagro y Fernández-Miranda 1978; Fernández-Miranda y Ruiz Gálvez 1980).

Desde un principio, nuestra interpretación arrancó encendidas manifestaciones críticas de otros estudiosos, defensores de presupuestos más 
tradicionales sobre la metalurgia de los epígonos prehistóricos peninsulares. Opiniones contrarias que se referían a la interpretación estratigráfica del yacimiento, la adecuación de la datación absoluta obtenida, los paralelos foráneos, el valor de la metalurgia atlántica y la conceptualización tipológica de los hallazgos metálicos. La amplia nómina de investigadores, disconformes con nuestra interpretación, puede seguirse en las citas de nuestras aportaciones incorporadas a este trabajo. Las calibraciones cronológicas acercaron algunas de esas posiciones extremas hasta nuestros presupuestos científicos en el debate. Al tiempo que las indagaciones tipológicas sobre la espada de la Miel, pese a muy concienzudos análisis morfológicos de trascendental valor (Brandherm 2007; Burgess y O'Connor 2008), podrían aproximarse (Mederos 2008) a las que venimos defendiendo (Carrasco y Pachón 2006a, b, c).

Nuestros presupuestos han ido encontrado sustento arqueológico en los últimos treinta años, gracias a la aparición de otras fíbulas en la Península Ibérica. Entre, ellas tienen especial importancia dos de la provincia de Granada: Casa Nueva, junto al yacimiento de Los Infantes de Pinos Puente y Guadix.

La fíbula de Casa Nueva es única en su género, por ser la primera que presenta un exorno decorativo peculiar. Consiste en dos botones de oro, dispuestos simétricamente en el centro de cada uno de los brazos del puente, a idéntica distancia a uno y otro lado del codo. Este elemento ornamental no es un simple aditamento decorativo, sino resultado de una sencilla readaptación estética para personalizar un objeto de uso más o menos corriente, dotándolo de un evidente signo de distinción (Carrasco y Pachón 2001).

La segunda fíbula procede del taller metalúrgico de Guadix (Carrasco et al. 2002), donde se localizó un centro de producción artesanal de bronces, incluyendo fíbulas "tipo Huelva", propio de un período cronológico tardío, en una zona que no había podido demostrar su pertenencia a los lugares de mayor afección orientalizante.

Recientemente, hemos definido y sistematizado la fíbula de codo "tipo Huelva", contraponiendo su abundante aparición en la Península Ibérica y su muy escaso reparto en ámbitos del Mediterráneo Oriental. Se ha descrito su distribución, tipología, origen y cronología (Carrasco y Pachón 2006a, b, c). El fin era realzar y revalorizar un producto metálico de fines de la Prehistoria pe- ninsular interpretado a partir de modelos hipotéticos, sin excesiva contrastación, para justificar variadas influencias exógenas y cronologías improbables. Nuestras investigaciones han analizado estas fíbulas desde parámetros arqueológicos: composición, tipología interna, asociación estratigráfica, cronología absoluta, dispersión geográfica, etc. De igual forma, se ha intentado definir el grupo denominado "Huelva" con caracteres y entidad propia (Carrasco y Pachón, 2006b), aislándolo del resto de las fíbulas de codo que, en cierto modo, entrarían en el grupo de las llamadas lisas o de "tipo sículo", renombradas por nosotros como "tipo Monachil" en reconocimiento al ejemplar estudiado por W. Schüle, procedente del Cerro de la Encina (Monachil, Granada) (Schüle, 1969: 144, Abb. 39b).

Un rasgo distintivo en estas producciones era la escasa presencia de estaño en las fíbulas "tipo Huelva", que parecía concentrarse en gran parte de los ejemplares procedentes de Granada y configuraba un grupo diferenciado de fíbulas, que podrían haber sido producidas allí (Carrasco et al. 1999). La sucesión de hallazgos sirvió para apoyar estas argumentaciones con referencias morfológicas suficientes para establecer una secuencia tipológica que incluía todos los modelos propios del "tipo Huelva" (Carrasco y Pachón 2006b). De la misma manera, se propuso una secuencia temporal de estos imperdibles con apoyo de dataciones absolutas y contextos asociados (Carrasco y Pachón 2006a). En último término, también se reflexionó sobre el viejo debate del origen oriental de estas fíbulas, considerando su probable autoctonía peninsular (Carrasco y Pachón 2006c).

\section{NUEVOS HALLAZGOS DE FÍBULAS DE CODO}

De las novedades que completan el panorama de lo conocido hasta 2006, destacamos 7 fíbulas de codo: 4 de "tipo Huelva" y una de "tipo liso" o "sículo", localizadas en el entorno del Cerro de los Infantes de Pinos Puente, Granada (Mendoza et al. 1981); otra de "tipo Huelva" del Castro de Laias en Barbantes, Orense (Álvarez y López 2000); y una extraordinaria fíbula de puente asimétrico, tipo tradicionalmente relacionado con ambientes sículos, de Las Lunas en Yuncler, Toledo (Urbina y García Vuelta 2010). Esta última 
formaba parte de un rico depósito broncíneo del Bronce Final.

Nuestro interés principal son las de "tipo Huelva", aunque la aparición ciertamente escasa de fíbulas de codo, no solo en el ámbito peninsular, sino mundial, obliga a referirse a las otras por haber sido estudiadas y relacionadas con las de "tipo Huelva", o porque nuestras investigaciones sobre ellas han sido mal interpretadas o confundidas.

\subsection{El Castro de Laias (Barbantes, Orense)}

También denominado $O$ Castelo, el asentamiento de Laias se localiza a $14 \mathrm{~km}$ al Oeste de Orense. Ocupa un promontorio de carácter granítico de unas 10 ha de extensión y una altura de 240 m s.n.m, proyectado abruptamente sobre la ribera derecha del río Miño. Estratégicamente situado sobre él, domina visualmente un amplio espacio geográfico de su cuenca media, con amplios recursos agrícolas y mineros.

El asentamiento, conocido por López Cuevillas desde principios del siglo $\mathrm{XX}$, fue excavado por Chamoso Lamas a partir de 1956, quien señaló una mina de oro explotada por Roma. En 1997, con motivo de las obras para la construcción de la autovía Rías Baixas que afectaban parcialmente este yacimiento, se iniciaron trabajos arqueológicos de urgencia en su parte superior y ladera media, antes de ser destruidas por las citadas obras civiles. Las excavaciones documentaron ocupaciones prehistóricas, protohistóricas y romanas (Álvarez y López 2000). Para sus investigadores, la ocupación más antigua, según dataciones absolutas, correspondería a los siglos IXVIII a.C., que ilustraría momentos finales del Bronce Final e inicios de la Edad del Hierro. Un poblamiento que continuó, de forma discontinua $\mathrm{y}$ con ocupaciones diferenciadas, hasta posiblemente los siglos III-IV d.C.

La posición estratigráfica de la fíbula de codo "tipo Huelva" (Fig. 1:1) nos es desconocida, pero a partir de las descripciones de sus excavadores intuimos que debió aparecer en estratos de habitación de sus primeros niveles de ocupación (Bronce Final). Este hallazgo amplía el espectro que teníamos sobre su dispersión peninsular, apoyados sobre todo por algunas de sus características tipológicas.

La fíbula está incompleta y es de bronce, con un alto grado de corrosión. Conserva el brazo derecho del puente con el resorte de muelle, compuesto por espira y media y parte de la aguja de sección circular. Aunque está partida, el codo es ligeramente abierto. Al brazo izquierdo del puente le falta el pie o mortaja. El puente, totalmente simétrico con el codo centrado, tiene una sección de media caña realzada. El perfil de la fíbula es de triángulo semi-equilátero. Las plantas de los brazos del puente son elipsoidales con fajas centrales realzadas y decoradas con ocho o nueve incisiones verticales paralelas, delimitadas a ambos lados por otras horizontales en fajas de tres o cuatro unidades. Es posible que entre las fajas centrales y el codo, en un sentido, y las fajas y el resorte y mortaja, por otro, tuviese finos collarines perdidos o disimulados por las concreciones y alteraciones debidas a la oxidación del metal. Dimensiones: longitud con la reconstrucción de la mortaja entre 8,5-9 cm; en la actualidad, sin mortaja, es de unos $7 \mathrm{~cm}$; alt. $4 \mathrm{~cm}$; anch. de las secciones máximas de los brazos $12 \mathrm{~mm}$; esp. 4 $\mathrm{mm}$. La sección circular de la aguja es de $3 \mathrm{~mm}$. Tab. 1: (PA12223).

Esta fíbula entraría en el tipo III de nuestra serie, denominada variante Meseta (Carrasco y Pachón 2006b), con tres subtipos a, b, c, caracterizados por las fíbulas de Alto de Yecla, Burgos (González-Salas 1936-40, 1945), Castro de la Cildad de Sabero, León (Celis 1998-1999) y Berrueco, Salamanca (Maluquer 1958). En este tipo se desarrollan exclusivamente las fajas centrales, constituyendo su máximo exponente decorativo, constriñéndose las laterales hasta conformar simples alambres, a veces con collarines. Posiblemente sea el conjunto menos conocido de todo el "tipo Huelva" por la escasez de su muestra, por desconocer los contextos arqueológicos en los que aparecieron y carecer de documentación gráfica, salvo la fíbula de Sabero. La de Alto Yecla y la del Berrueco se han reconstruido a partir de antiguas fotografías.

En la fíbula de Laias, las fajas centrales no extralimitan sus contornos elipsoidales, pero sí realzan el perfil de los brazos del puente. La decoración vertical de estas fajas difiere de las meseteñas: reticulados en la de Alto Yecla, reticulados e incisiones paralelas en las de Sabero, e incisiones paralelas en la de Berrueco. En su momento, considerábamos que este tipo III representaba la forma más desarrollada del "tipo Huelva". Lo fechamos en el siglo IX, e incluso principios del VIII a.C., basándonos en sus desarrollos 


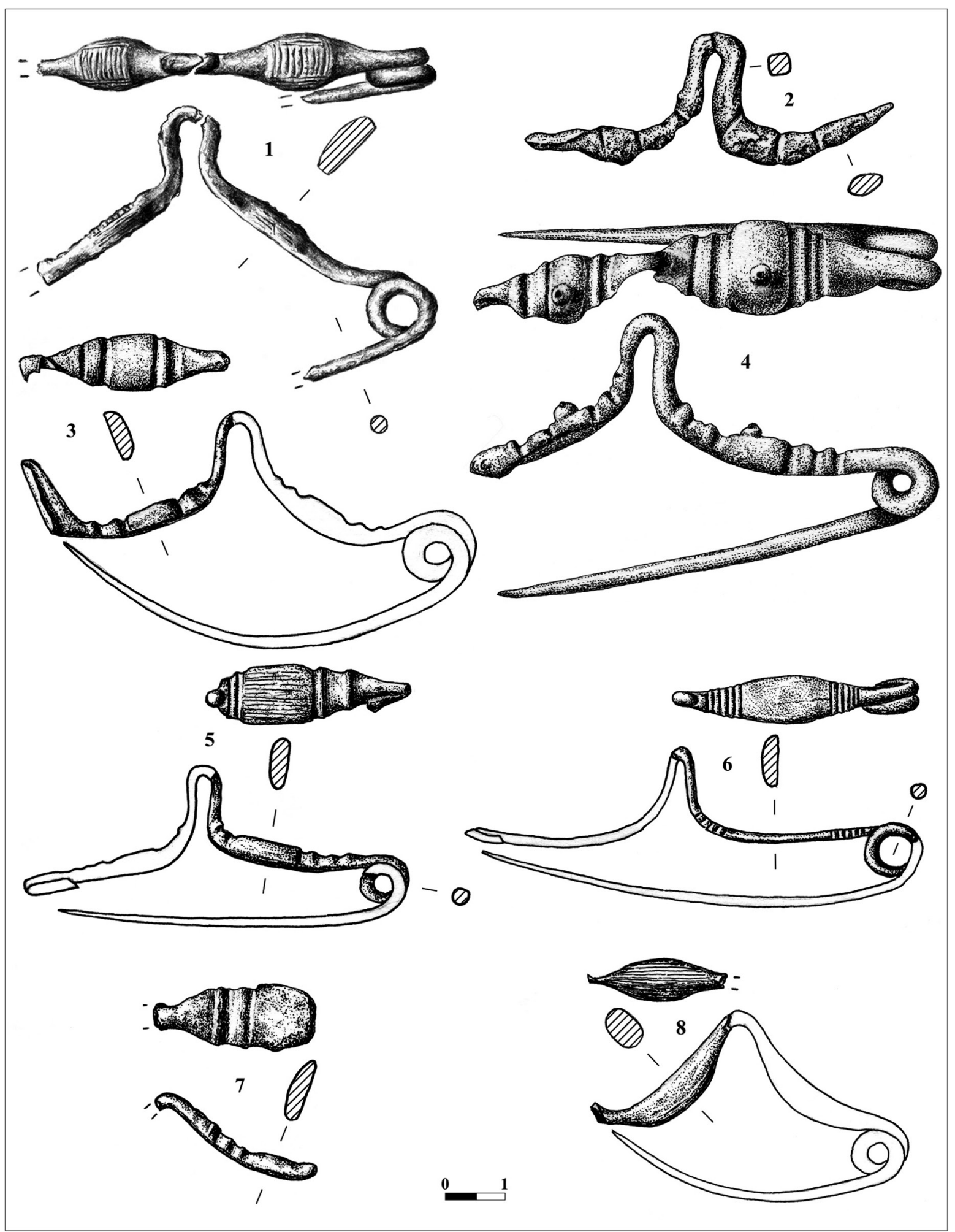

Fig. 1. Nuevas fíbulas de codo: 1. Laias, Ourense; 2 y 3. Cerro de los Infantes, Pinos Puente, Granada; 4 y 5. Ribera del río Velillos, Casa Nueva, Granada; 6 a 8. Cerro de las Agujetas, Pinos Puente, Granada. 


\begin{tabular}{|l|l|c|c|c|c|c|c|c|c|c|}
\hline N. ${ }^{\circ}$ Análisis & \multicolumn{1}{|c|}{$\begin{array}{l}\text { Yacimiento } \\
\mathbf{y} \text { tipología }\end{array}$} & $\mathbf{F e}$ & $\mathbf{N i}$ & $\mathbf{C u}$ & $\mathbf{Z n}$ & $\mathbf{A s}$ & $\mathbf{A g}$ & $\mathbf{S n}$ & $\mathbf{S b}$ & $\mathbf{P b}$ \\
\hline PA20250 & $\begin{array}{l}\text { C. Nueva. } \\
\text { Codo, t. Huelva }\end{array}$ & 0,10 & $\mathrm{nd}$ & 90,8 & $\mathrm{nd}$ & $\mathrm{nd}$ & $<0,2$ & 9,0 & $<0,2$ & 0,09 \\
PA20251 & $\begin{array}{l}\text { C. Agujetas. } \\
\text { Codo, t. Huelva }\end{array}$ & 0,91 & $\mathrm{nd}$ & 84,5 & $\mathrm{nd}$ & $\mathrm{nd}$ & $<0,2$ & 14,2 & $<0,2$ & 0.36 \\
PA20252 & $\begin{array}{l}\text { C. Infantes. } \\
\text { Codo, t. Huelva }\end{array}$ & 0,12 & $\mathrm{nd}$ & 88,1 & $\mathrm{nd}$ & $\mathrm{nd}$ & $<0,2$ & 11 & $<0,2$ & 0,71 \\
PA20253 & $\begin{array}{l}\text { C. Agujetas. } \\
\text { Codo, t. Huelva }\end{array}$ & 0,11 & $\mathrm{nd}$ & 91,0 & $\mathrm{nd}$ & $\mathrm{nd}$ & $<0,2$ & 8,88 & $<0,2$ & 0.05 \\
PA20254 & $\begin{array}{l}\text { C. Agujetas. } \\
\text { Codo, "lisa" }\end{array}$ & 0,14 & $\mathrm{nd}$ & 87,9 & $\mathrm{nd}$ & $\mathrm{nd}$ & $<0,2$ & 11,9 & $<0,2$ & $\mathrm{tr}$ \\
PA12223 & $\begin{array}{l}\text { C. de Laias. } \\
\text { Codo, t. Huelva } \\
\text { C. Nueva. }\end{array}$ & $\mathrm{nd}$ & $\mathrm{nd}$ & 84,2 & $\mathrm{nd}$ & $\mathrm{nd}$ & 0,19 & 14,2 & 0,19 & 0,71 \\
ICP-MS001 & $\begin{array}{l}\text { Codo, t. Huelva } \\
\text { Las Lunas. } \\
\text { Codo, "sícula" }\end{array}$ & 0,65 & $\mathrm{nd}$ & 86,6 & $\mathrm{nd}$ & $\mathrm{nd}$ & 0,06 & 11,8 & $\mathrm{nd}$ & 0,85 \\
\hline
\end{tabular}

Tab. 1. Composición elemental de las fíbulas de codo. Todas se han analizado por Fluorescencia de Rayos X (FRX) dentro del Proyecto Arqueometalurgia de la Península Ibérica, salvo la de Casa Nueva (ICP-MS001) analizada por espectrometría de masas en los Servicios Técnicos de la Universidad de Granada. En la serie PA10000 se ha empleado el espectrómetro Metorex X-MET 920MP con detector de $\mathrm{Si}(\mathrm{Li})$ y fuente de $\mathrm{Am}^{241}$; valores expresados en \% en peso (nd= no detectado; tr= trazas; los límites de detección son del 0,01\% para todos los elementos, salvo Ag y Sb fijado en el 0,001\%); los análisis PA20000 han empleado el equipo portátil INNOV-X serie Alpha con tubo de rayos X; valores expresados en \% en peso (nd= no detectado; los límites de detección son de $0,04 \%$ para todos los elementos menos Ag y Sb que es el 0,2\%). Pinos Puente (Granada): C. Nueva = Casa Nueva, C. Agujetas = Cerro de Las Agujetas, C. Infantes $=$ Cerro de Los Infantes; C. Laias = Castro de Laias (Barbantes, Orense); Las Lunas (Yuncler, Toledo). t. = tipo.

morfo-tipológicos y en su análisis elemental. La cronología de la de Laias no debería bajar de la primera mitad del siglo IX, dada su configuración tipológica y composición de bronce binario rico en estaño.

\subsection{El complejo arqueológico de Cerro de los Infantes (Pinos Puente, Granada)}

El Cerro de los Infantes es un asentamiento en el borde noroccidental de la Vega de Granada, a unos $15 \mathrm{~km}$ de la capital. Ocupa una serie de colinas de calcarenitas de diferentes alturas en la orilla derecha del río Velillos o Frailes, un curso permanente de agua que conforma uno de los postreros afluentes del río Cubillas, poco antes de confluir en el Genil. En tiempos prerromanos, aquellos dos importantes suministros hídricos desembocaban directamente en la Vega de Granada, entonces un fondo pantanoso más o menos practicable a lo largo del año. El sitio arqueoló- gico de Los Infantes debió prosperar en relación directa con el progresivo desecamiento del fondo de la depresión, y el consiguiente aumento de sus posibilidades agropecuarias. Una pequeña meseta en el área de mayor altura (cota 652 m.s.n.m.), con forma más o menos redondeada, se denomina Cerro Corona.

La secuencia crono-cultural pudo originarse en el III milenio a.C., aunque sin garantías de que hubiese pertenecido a un hábitat estable. Un pequeño reducto en la parte noroeste ha podido fecharse en tiempos argáricos. La continuidad desde estos momentos tampoco ha podido comprobarse, porque no se han reconocido vestigios de lo que en Andalucía Oriental denominamos Bronce Tardío. A partir del Bronce Final sí habría una continuidad poblacional con la que fue factible alcanzar la época romana: Municipium Ilurconensis (Pastor 2002: 97-115). En la Edad Media se abandonaría definitivamente, probablemente en favor de la actual población de Pinos Puente (Peinado 1998). 
En la década de 1980 los cortes practicados en la parte suroriental, por el Museo Arqueológico Provincial y la Universidad de Granada, permitieron analizar una potente secuencia estratigráfica comprendida entre el Bronce Final y el horizonte Ibérico Antiguo (Mendoza et al. 1981). Entre sus resultados destaca la aparición de una fíbula de codo "tipo Huelva" bien contextualizada, además de un horno de producción de ánforas de tipo fenicio y de cerámicas grises, probablemente activo a lo largo del siglo VI a.C. (Contreras et al. 1983).

Frente al Cerro de los Infantes, por su parte sureste, en la orilla izquierda del río Frailes se levanta el más humilde Cerro de las Agujetas (cota 609 m.s.n.m.), donde los restos funerarios se asocian a vestigios más variados que apuntarían hacia el uso prolongado con funciones diversas de este anejo del Cerro de los Infantes.

Más al oeste, aguas abajo, a unos $500 \mathrm{~m}$ de las últimas evidencias arqueológicas de Infantes, encontramos la denominada Casa Nueva, extendida por las terrazas aluviales, de donde procederían otros elementos fibulares que comentaremos.

Los tres sitios arqueológicos citados configuran una única agrupación de mayor entidad, constituida en torno al propio Cerro de los Infantes, con diferentes necrópolis que cubrieron las necesidades funerarias de sus habitantes y áreas productivas complementarias del asentamiento.

\subsubsection{Cerro de los Infantes}

En las excavaciones de 1980 se recuperó una fíbula de codo en el estrato 3 del corte 23 , perteneciente al horizonte III del yacimiento, correspondiente a un pleno Bronce Final, que se fechó entre el 900 y el 750 a.C. (Mendoza et al. 1981). Su lamentable estado de conservación hizo necesario un dibujo rápido y su entrega inmediata al restaurador del Museo Arqueológico de Granada. $\mathrm{Su}$ configuración actual no la conocemos. La documentación presentada responde al original publicado por sus autores (Fig. 1: 2). Su mal estado impidió, según F. Molina, su análisis elemental.

La publicación no aclaró la distribución de los materiales en los estratos del horizonte III de Los Infantes, por lo que desconocemos si la fíbula procede de los rellenos más altos o de los inferiores. En la actualidad, la datación del 750 a.C. debiera elevarse de acuerdo con los hallazgos de La Mora. Aquí, las primeras importaciones fenicias se fecharon por C14 sin calibrar en el 790 a.C. Como la fíbula se asociaba con cerámicas con decoración incisa de tipo Camporchanes/Cabezo Colorado, los excavadores hablaron de un Bronce Final Pleno, que situaron en el siglo X a.C. La presencia en ese mismo horizonte de cerámica con decoración bruñida es de gran interés para la datación de las fíbulas.

El ejemplar de Los Infantes carece de resorte, aguja y pie. El codo, algo abierto, aparece centrado en el puente, siendo su sección seudo-cuadrangular. Los brazos del puente son de sección lenticular, presentando una decoración compuesta, al menos, por tres incisiones perpendiculares que hacen resaltar fajas lisas. El mal estado de conservación impide mayores precisiones. Dimensiones: alt. total $23 \mathrm{~mm}$; long. total $64 \mathrm{~mm}$; sección del codo $4 \mathrm{~mm}$; sección media del puente $6 \mathrm{~mm}$ (Fig. 1:2).

Hemos documentado una segunda fíbula descontextualizada, procedente de la ladera oriental del yacimiento, cuya mejor caracterización morfométrica complementaría los datos del ejemplar anterior. Se trata del brazo izquierdo de una fíbula de codo "tipo Huelva" de sección de media caña, que conserva el pie o mortaja y parte del codo. La decoración está compuesta por una faja central que no sobresale de la planta elipsoidal del brazo, enmarcada por dos incisiones desarrolladas que, a su vez, constriñen unos anillos o collarines por ambos lados. De igual forma, resaltan y delimitan las zonas del codo y del pie. Dimensiones: long. $3,5 \mathrm{~cm}$; anch. máx. en el centro de la faja central $0,9 \mathrm{~cm}$; esp. máx. $0,4 \mathrm{~cm}$. Esta fíbula, según nuestra reconstrucción, debía tener una longitud en torno a los 7,5-8 cm. Muy posiblemente, por la disposición de la mortaja y la configuración del brazo, la aguja sería curva, lo que a priori no deja de ser un rasgo de modernidad (Tab. 1: PA20252) (Fig. 1: 3).

En principio, entraría en nuestro tipo II (Carrasco y Pachón 2006b), subtipos Ib2-IIab1/IIab2. Básicamente se caracterizan porque las incisiones, que enmarcan las fajas centrales, se abren dando paso a unas acanaladuras profundas y abiertas que convierten las estrechas fajas laterales en molduras. Entre sus peculiaridades controvertidas y antagónicas están la ausencia de decoraciones incisas, una faja central sin sobresalir de la configuración elipsoide de la fíbula y moldu- 
raciones poco desarrolladas que centran la faja central; rasgos que indicarían antigüedad en el tipo. En cambio, la posible curvatura de la aguja sugeriría cierta modernidad. Su análisis elemental arroja un porcentaje de estaño que sobrepasa ligeramente el $10 \%$ e impurezas de plomo $(0,71 \%)$. Sus paralelos más evidentes serían la fíbula Guadix A (Ib2) (Carrasco y Pachón 2002 y 2004) y uno de los ejemplares de la Ría de Huelva (IIab1) (Almagro Basch 1958: E.1, 39 (38) n. ${ }^{\circ} 262$; RuizGálvez 1995a: lám.11, 25). Por las características controvertidas que hemos apuntado sobre esta fíbula, la fecharíamos entre la segunda mitad del siglo $\mathrm{X}$ y la primera mitad del IX a.C.

\subsubsection{Casa Nueva (Pinos Puente, Granada)}

La terraza, donde al parecer se encontró la primera fíbula (Carrasco y Pachón 2001) y posteriormente la segunda, carecía de material arqueológico parangonable con el que mostraremos después en el Cerro de las Agujetas, lo que dificulta una interpretación razonable de su origen. No obstante, se han recuperado allí restos muy fragmentarios de cerámicas a mano horneadas en ambientes de reducción, sin demasiados indicios sobre su tipología, pero suficientes para adjudicarlos sin muchas dudas al Bronce Final. Junto a ellos, se han recogido botones cónicos que algunos autores identifican como de atalajes de caballos, o complementos más imprecisos de carros.

La interpretación más plausible es que el sitio fue un lugar de acumulación de los vestigios arqueológicos que el río Frailes erosionó, aguas arriba, en los yacimientos de Infantes y Agujetas, que limitaban directamente con su cauce. Cabe también la posibilidad de que los escasos restos existentes en el lugar procedieran de depósitos in situ, probablemente de naturaleza funeraria, considerando la importancia del exorno áureo ostentado en el puente de una de las fíbulas.

La primera fíbula (Carrasco y Pachón 2001) está casi completa. Solo le falta una parte del pie o mortaja, cuyo arranque conserva. El resorte es de dos espiras, con la novedad de acomodarse a la izquierda del puente, tomando como orientación el pie de la fíbula, como algún ejemplar de la Ría de Huelva. El resto de ejemplares, de la provincia de Granada, presentan el resorte a la derecha. El puente, con sección de media caña y perfil elíptico aplanado por la base, tiene las fajas centrales de sus brazos resaltadas a ambos lados por tres amplias incisiones en el brazo derecho y dos en el izquierdo. Ambas fajas carecen de decoraciones incisas, pero ofrecen un pequeño botoncito de oro, que hoy resalta sobre el fondo oscuro del bronce. La aguja es plana y el codo, ligeramente abierto, está centrado. Dimensiones: long. máx. en el puente $81 \mathrm{~mm}$, sección media de la aguja $3 \mathrm{~mm}$; sección media del brazo $6,5 \mathrm{~mm}$; anch. máx. del brazo $17 \mathrm{~mm}$; diám. máx. de las espiras $12 \mathrm{~mm}$; diám. máx. de los botones de oro 2,5 mm; altura máx. de los botones $2 \mathrm{~mm}$. La reconstrucción de la fíbula daría una dimensión máxima aproximada de $90 \mathrm{~mm}$ (Tab. 1: ICPMS001) (Fig. 1: 4).

Inicialmente, la situamos en el tipo I, el más antiguo tras el ejemplar del Cerro de la Miel, por cuyas características tecnotipológicas lo denominamos subtipo Ia1. Constituye la versión de prestigio del tipo I del que se diferencia exclusivamente por la decoración del puente, con los dos botones de oro en las fajas anchas de sus brazos, junto a las incisiones más desarrolladas que separan las fajas decorativas. Su cronología no debe bajar del siglo XI a.C, cuando la del Cerro de la Miel pudo tener su origen durante el siglo XI e incluso a fines del XII a.C. (Carrasco y Pachón 2006c). Esta fíbula y la del Museo de Eretria (vitrina 5, n. ${ }^{\circ}$ 8690), procedente de Lefkandi (Euboia), que estudiamos a principios del año 2000 (Carrasco y Pachón 2006a), comprobando errores tipológicos de Buchholz (1985: fig. 3: 11), constituyen los únicos testimonios que conocemos del empleo de oro en la elaboración o decoración de fíbulas de este tipo en el Mediterráneo.

El nuevo fragmento de fíbula de codo "tipo Huelva" conserva parte del brazo derecho del puente, con restos del resorte de muelle e inicios del codo. La faja central, decorada con finas incisiones paralelas, sobresale ligeramente del contorno elipsoidal del brazo. Está centrada a la derecha por dos incisiones que contienen una suave y estrecha faja que, a partir de un fino collarín, da paso a la zona del resorte. La sección es de fina media caña. Por su parte izquierda, de igual diseño que la anterior y menores dimensiones, otra incisión delimita los inicios del codo. Dimensiones: long. máx. $4 \mathrm{~cm}$; anch. máx. en la faja central $1 \mathrm{~cm}$, esp. $0,3 \mathrm{~cm}$. Reconstruida mide unos $7 \mathrm{~cm}$. Contiene 9,0\% de $\mathrm{Sn}$ (Tab. 1: PA20250) (Fig. 1: 5). 
La asimilamos, con matizaciones, a nuestro subtipo IIab2 (Carrasco y Pachón 2006b), representado por un ejemplar de la Ría de Huelva (Almagro Basch 1958: E.1.39 (38) n. ${ }^{\circ}$ 259; RuizGálvez 1995: lám. 11, 22). En este tipo, la faja central sobresale del contorno del brazo y se diluyen las incisiones que la enmarcan como las pequeñas fajas laterales. Esta fíbula puede fecharse entre finales del siglo $\mathrm{X}$ y principios del IX a.C.

\subsubsection{Cerro de las Agujetas (Pinos Puente, Granada)}

El conocimiento actual del yacimiento se basa en hallazgos ocasionales, pero estos datos aproximativos son de un indudable interés (Pachón et al. 1979: 324-329; Pachón y Carrasco 2009, 2010). Recientemente se han realizado excavaciones de urgencia en este lugar, desconociéndose sus resultados. El sitio, quizás de forma esporádica, pudo ser una de las necrópolis del poblado arcaico del otro lado del río. Entre sus elementos metálicos destacan tres fíbulas de codo y otra tartésica de bronce tipo Alcores, recuperada en las inmediaciones del yacimiento, en la vaguada que -a oriente- lo separa de Cerro Granados.

En definitiva, el Cerro de las Agujetas conforma un pequeño enclave de clara función complementaria respecto de Los Infantes, probablemente frecuentado desde fines de la Edad del Bronce y que prolongaría su uso hasta tiempos romanos. Aunque es probable que albergara algún reducto funcional de carácter económico e incluso militar, una parte importante de los hallazgos también aluden a la presencia de núcleos de utilidad funeraria, de los que podrían proceder las tres fíbulas de codo que presentamos.

A. Descripción (Fig.1: 7): fragmento de brazo del puente con restos del codo de una fíbula "tipo Huelva". Presenta faja central remarcada sin decoración, con tres amplias incisiones que enmarcan, a su vez, dos collarines que la separan del área del codo. Su fragmentación no permite ir mucho más allá. Dimensiones: long. $3 \mathrm{~cm}$; anch. en la faja central $1,2 \mathrm{~cm}$. No hemos intentado reconstruirla, pero pudo ser grande: unos $9 \mathrm{~cm}$. Podría corresponder al subtipo IIab2 y fecharse entre fines del siglo $\mathrm{X}$ y primera mitad del IX a.C. (Tab. 1: PA20253).
B. Descripción (Fig. 1: 6): brazo derecho del puente con resorte y parte del codo de una fíbula "tipo Huelva". De planta elipsoidal, presenta una faja central no resaltada, lisa, enmarcada entre una faja con seis finas incisiones paralelas que la separan del área del resorte $\mathrm{y}$, otra, con cinco incisiones similares, por su parte izquierda, que la separan del área de codo. El resorte de muelle conserva una espira. Es muy plana, con una fina sección de media caña. Dimensiones: long. 4,5 cm; anch. máx. 0,8 cm; esp. $2 \mathrm{~mm}$. Reconstruida mediría unos $9 \mathrm{~cm}$ (Tab. 1: PA20251).

La situamos como un subtipo nuevo de nuestra serie Huelva, por carecer de fajas bien delimitadas con incisiones profundas, collarines, etc. y por su sobriedad: muy lisa y relativamente plana. Quizás, la más parecida sea la procedente de la Calle San Miguel (Guadix) (Carrasco et al. 2002), paradigma del subtipo Ic1, que apenas desarrolla las decoraciones en el puente, propias de estas fíbulas. Por su composición, con un alto porcentaje de estaño $(14,2 \%)$, también se asemeja a la accitana de San Miguel, hasta la fecha el ejemplar granadino con más estaño $(13,1 \%)$. Y, como a ella, la datamos en torno al último tercio del siglo IX a.C.

C. Descripción (Fig. 1: 8): fragmento del brazo izquierdo de una fíbula lisa de codo, de las tradicionalmente denominadas "sículas". De configuración elipsoidal, la máxima sección en el centro se afina hacia el codo y pie. Su parte inferior está decorada con diez finas líneas paralelas incisas, que pudieron existir en menor número por la parte superior o exterior. Conserva el inicio del pie o mortaja, insinuándose también parte del codo. Dimensiones: long. máx. 0,28 cm, sección oblonga máx. $8 \times 6 \mathrm{~mm}$. Peso 3 gr. Su longitud reconstruida rondaría los $5 \mathrm{~cm}$ con el codo centrado en el puente. Se fundió en un bronce de aleación media $(9,0 \% \mathrm{Sn})$ y pocos oligoelementos (Tab. 1: PA20254).

Este fragmento no entra en los parámetros del "tipo Huelva". Es idéntica a la localizada en la Ría de Huelva, que Almagro Basch (1966: fig. 74, 1) definió como sícula a partir de una hipotética reconstrucción. Como comentario previo a la discusión sobre el origen de las fíbulas lisas, diremos que la fíbula de Agujetas comparte rasgos decorativos, morfo-técnicos y tipológicos con muchas otras de codo peninsulares. La cronología, como pudo tener la onubense, debe corresponder grosso modo a la primera mitad del si- 
glo IX a.C., paralela en el tiempo y, en territorios andaluces, a las últimas producciones de las de "tipo Huelva".

\subsection{Las Lunas (Yuncler, Toledo)}

El sitio ocupa un espacio en torno a las 10 ha. Las actuaciones arqueológicas se centraron en una superficie de 1 ha, documentándose un hábitat con dos momentos de ocupación: en época romana y Bronce Final/Hierro (Urbina y García Vuelta 2010). Las noticias del registro cerámico son aún muy incompletas.

Las excavaciones localizaron, en el sector H-8, un depósito broncíneo próximo a una estructura circular, apoyada en un estrato arenoso, sobre una superficie ocre endurecida con restos de barro quemado. Lo componían veinte objetos de bronce, entre herramientas, elementos de adorno y restos de fundición. Interesa en particular una fíbula de codo descentrado (Urbina y García Vuelta 2010: 181, fig. 4: L-10), que conserva el brazo izquierdo del puente y parte del resorte (Fig. 2), faltando el codo, la aguja, la parte derecha del puente y el pie o mortaja. El fragmento, de sección circular oblonga y $1 \mathrm{~cm}$ de diám. medio, alcanza 10,7 cm de long., decorado con fajas rellenas de finos reticulados incisos que alternan con otras más lisas con rombos sin rellenar, separadas por estrechas fajas que conforman dos o tres líneas incisas paralelas. Conociendo la tipología de estas fíbulas, el ejemplar se aproximaría a 12 ó $13 \mathrm{~cm}$. de longitud, pie incluido y superaría los $50 \mathrm{~g}$ de peso. Es poco funcional y más apropiada como objeto representativo o de prestigio. Los autores, a partir de la bibliografía, relacionan sus extraordinarios y poco frecuentes caracteres morfométricos con modelos tipológicos que no nos parece que tengan que ver con ella. Tampoco reconocemos las consideraciones tipológicas y culturales que los autores nos atribuyen.

Por su gran tamaño, la fíbula de Las Lunas se paraleliza con modelos de la fase IIB de la necrópolis siciliana de Cassibile (Urbina y García 2010: 189). La comparación puede ser correcta, pero los paralelos peninsulares aducidos la debilitan. Es evidente su relación tipológica con la fíbula publicada por Almagro Basch $(1957,1966)$, procedente del Servicio de Investigaciones Prehistóricas (SIP) de Valencia. También, aunque no

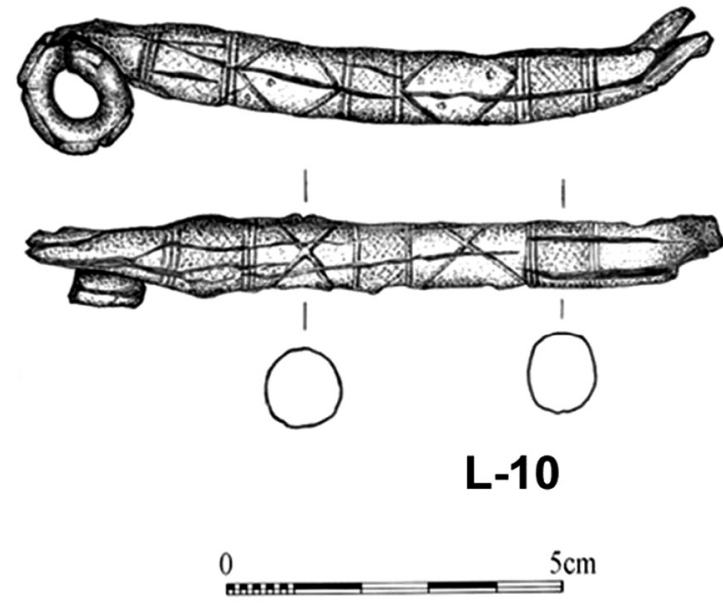

Fig. 2. Fíbula de codo de Las Lunas (Yuncler, Toledo), según Urbina y García Vuelta (2010: fig 4: L-10).

se mencione, puede cotejarse con el considerado ejemplar antiguo del Berrueco (Delibes 1981), a partir de la documentación del Padre Morán. Su puente asimétrico podría tener alguna relación con la fíbula del castro extremeño de "El Cerro de La Muralla" (Alcántara, Cáceres) (Fig. 3: 6), que presenta incisiones paralelas en los brazos del puente (Esteban 1988). El ejemplar de tipo Enkomi documentado en "Pajares" (Villanueva de La Vera, Cáceres), mal definido como "fíbula de arco" (Celestino 2001: 205, fig. 51), también, con cierta imaginación, podría entrar en el grupo de puente asimétrico, en lugar de incluirse entre las de violín como propone Giesen (2001).

\section{CUESTIONES FORMALES PARA EL ORIGEN Y EVOLUCIÓN TIPOLÓGICA DE LAS FÍBULAS}

\subsection{Simetría del puente en las fíbulas de codo lisas}

M. Almagro Basch propuso dos reconstrucciones de la fíbula lisa de la Ría de Huelva. En la primera, Almagro (1957: fig. 1: 10) dispuso el fragmento de forma más vertical, lo cual consideramos más correcto, añadiéndole el brazo derecho más inclinado y de mayores dimensiones, con una aguja relativamente plana (Fig. 4: 1). Posteriormente (Almagro 1958: E.1 39 (38) 267)

Trab. Prehist., 69, N. ${ }^{\circ}$ 2, julio-diciembre 2012, pp. 310-331, ISSN: 0082-5638

doi: $10.3989 /$ tp.2012.12094 


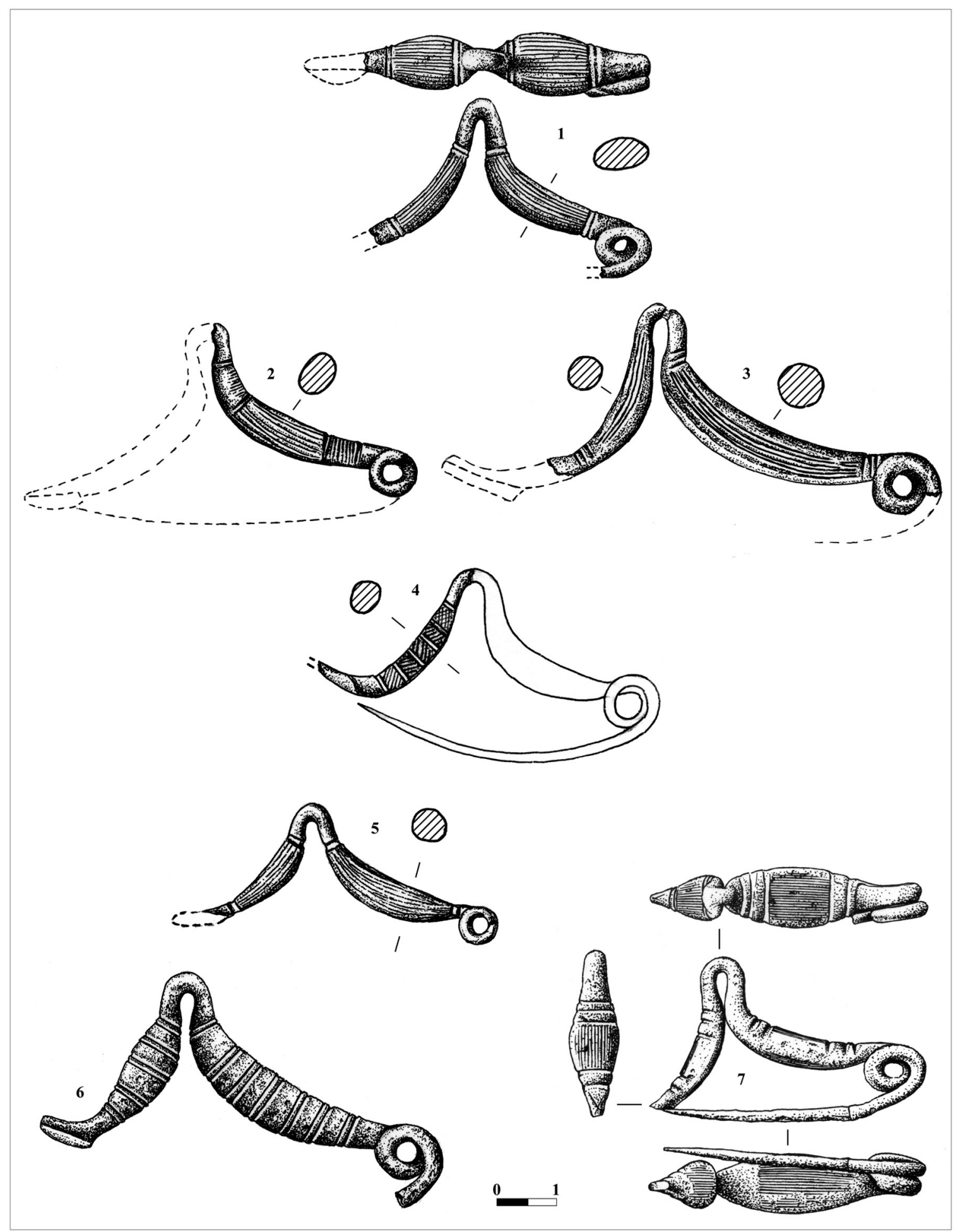

Fig. 3. Fíbulas de codo peninsulares, españolas y portuguesas en comparación con algún tipo italiano: 1. El Coronil, Sevilla; 2 y 3. Mondim da Beira, Viséu. 4. Monte Airoso (Penedono); 5. Castellucio, Ragusa; 6. Cerro de la Muralla, Alcántara/Garrovillas, Cáceres; 7. San Román de Hornija, Valladolid (Según G. Delibes). 
inclinó el brazo conservado y, a su vez, aplanó la reconstrucción del derecho a partir de una mayor inflexión, con una aguja totalmente plana (Fig. 4: 2). El propósito era reconstruir una fíbula de codo plenamente asimétrica, al estilo de las existentes en las necrópolis sicilianas de Cassibile. A partir de estos trabajos, documentados exhaustivamente con ejemplares de muy diversa tipología: sicilianos, chipriotas e incluso micénicos, elaboró un modelo de fíbulas asimétricas que se ha mantenido largo tiempo. Ese modelo, en cierta forma, condicionó la caracterización del "tipo Huelva", al forzar reconstrucciones con puentes de codo asimétrico.

La configuración del fragmento casi completo de brazo izquierdo del ejemplar, con restos de mortaja y de codo, de $0,34 \mathrm{~mm}$ de longitud, admitiría otra reconstrucción más adecuada. Es posible otra propuesta con alzado seudotriangular y codo más o menos centrado, similar a otras fíbulas conocidas en la Península Ibérica y, en menor medida, en otros ámbitos mediterráneos, denominadas grosso modo de "tipo Monachil" (Carrasco et al. 1999).

La mayoría de las fíbulas peninsulares que pertenecen al "tipo Huelva", o "Monachil", tienen el codo centrado, aunque la falta de la mortaja en muchas de ellas deforma la visión original, creando una asimetría inexistente. Como el brazo derecho sustenta el resorte, y suele ser mecánicamente más potente, puede distorsionar las medidas reales de ambos brazos del puente.

Igual sucede con las fíbulas ad occhio peninsulares, como las de Perales del Río (Blasco 1987), Mola d'Agrés (Gil-Mascarell y Peña 1989), Soto de Tobilla (Quintana y Cruz 1996; Cruz y Quintana 1999; Rodríguez 2009), Casal do Meio (Spindler 1973), S. Româo de Seia (Senna-Martínez 1995), la dudosa de Santa Luzia de Viséu (Kalb 1978), etc., que tienen el bucle centrado, en contraste con el asimétrico de los tipos 16 y 18 de Cassibile (Turco 2000: tav. XXIX). Las fíbulas peninsulares que denominamos "lisas" o "tipo Monachil", como el ejemplar comentado de la Ría y el de Agujetas, constituyen un cómputo no menor de veinte ejemplares, en gran parte inéditas, tienen un puente simétrico con el codo centrado. Por el contrario, son concretos y minoritarios los ejemplares que ofrecen un puente asimétrico y codo abierto o sugerido, entre las que se puede incluir la de Las Lunas de Toledo (Urbina y García Vuelta 2010). Aunque, si se

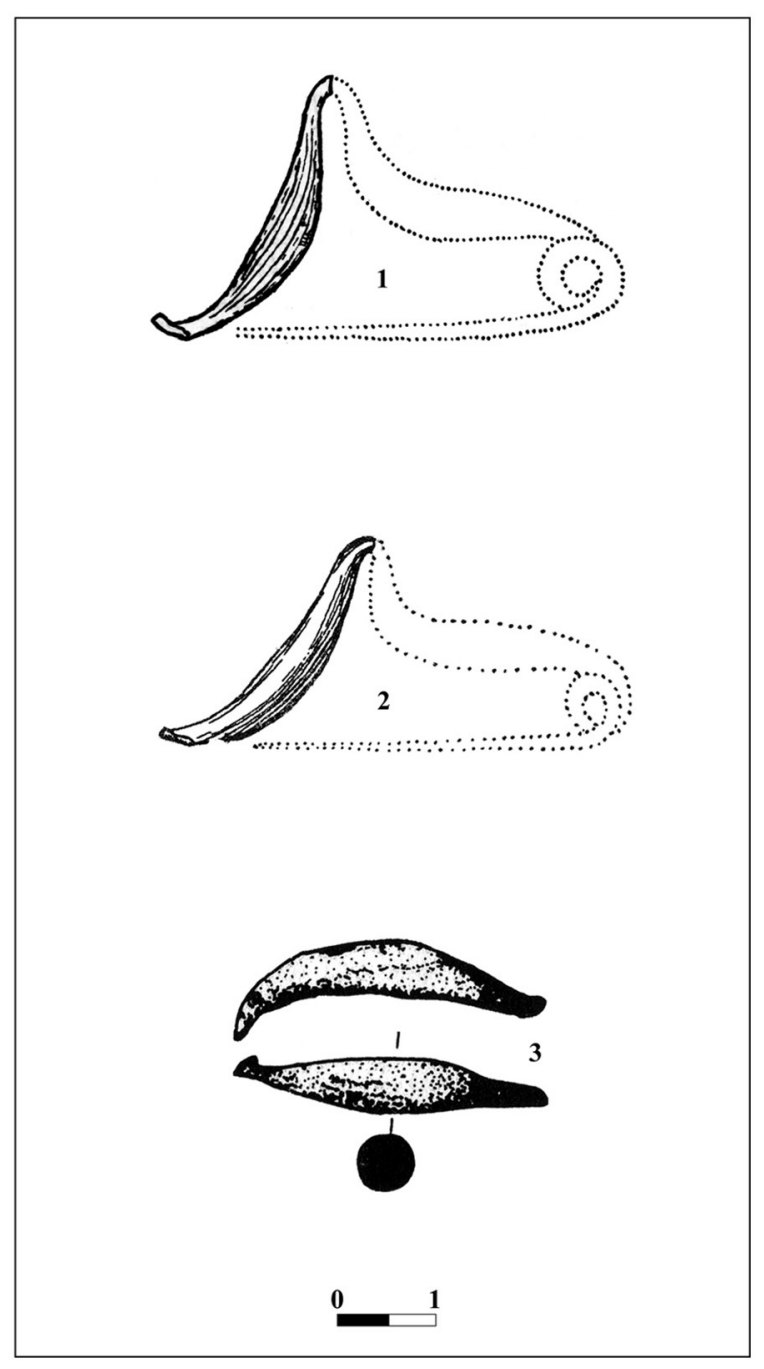

Fig. 4. Evolución gráfica de la fíbula sícula de la Ría de Huelva: 1. Almagro 1957; 2. Almagro 1958; 3. RuizGálvez 1995.

suman con las representadas en las estelas extremeñas y portuguesas, serían mayoritarias.

La reconstrucción de la fíbula lisa de Agujetas se ha basado en las características físicas del brazo conservado, que no pudo tener puente asimétrico. El codo, constituido por un estrechamiento extremo centrado, solo puede sustentar y equilibrar dos brazos similares. El derecho debió mantener un mínimo resorte y una fina aguja, con una cierta curvatura para ser acogida en una mortaja poco desarrollada e inclinada en el izquierdo. Con este tipo de configuración, se podrían relacionar sin excesivas complicaciones cuatro o cin- 
co fíbulas de las denominadas lisas con codo centrado, con una asimétrica, por su aspecto amorcillado y con otra del "tipo Huelva", también de sección oblonga, por su decoración en la parte inferior del puente.

En el grupo de las lisas mencionamos, en primer lugar, el ejemplar de El Coronil (Fig. 3: 1) (Carrasco y Pachón 2006b: tab. 2, IIb2). Su descubridor (Ruiz Delgado 1989) la incluyó en su grupo I, 1b, caracterizado por un puente masivo y sección ovalada, asimilándola con los ejemplares de la Ría de Huelva. En alguna ocasión la hemos incluido con dudas en nuestro "tipo Huelva", especialmente por el poco o inexistente desarrollo de las fajas del puente y por un anómalo alto porcentaje de hierro en su composición (3,42\%) (Ruiz Delgado et al. 1991). Las pequeñas dimensiones, sección oblonga del puente y codo centrado de esta fíbula, la asemejan en cierta forma a la que estudiamos, aunque no tanto por las fajas decorativas del puente.

Las dos fíbulas portuguesas de Mondim da Beira (Fig. 3: 2-3) y Monte Airoso (Fig. 3: 4) son de sección oblonga, con diseños de fajas incisas encima del puente, similares a las de El Coronil. Vilaça (2008) ha recogido algunos de nuestros comentarios sobre su historia (Carrasco y Pachón 2006c) que en su momento reinterpretamos, comprobando la mayor simetría de los brazos respecto de la posición más centrada del codo.

Estas cuatro fíbulas podrían ser derivaciones tardías colaterales del "tipo Huelva", basándonos "en los diseños incisos que parecen delimitar fajas, aunque no se trate de molduraciones, pero que en cierta forma recuerdan los mismos patrones decorativos que las onubenses" (Carrasco y Pachón 2006c: 280).

Ninguna de ellas, ni la de Agujetas, ni la del depósito de la Ría de Huelva, pudieron dar lugar a las del "tipo Huelva", ni por configuración, ni por tipología, ni por su composición, algunas ternarias y otras con gran cantidad de estaño. Tampoco tienen nada que ver con las sicilianas de Cassibile, donde no se han documentado. Un solo ejemplar puede entrar en este grupo: una pequeña fíbula sin mortaja, que tendría el codo centrado y el puente con decoración similar a la de El Coronil, procedente de la necrópolis siciliana de Castelluccio (Fig. 3: 5), Ragusa (GiumliaMair et al. 2010: fig. 11), clasificada en el tipo 290.2 (5279 B), sin más especificaciones. Difiere del resto de las fíbulas de puente asimétrico, pero un solo caso no hace un tipo, existiendo más ejemplares en la Península Ibérica que en Sicilia para comprenderlo. En consecuencia, en principio, el depósito de la Ría de Huelva no mostraría influencias sículas, al menos en lo relacionado con los elementos fibulares.

Por su aspecto, como diría Almagro Basch, amorcillado, y brazos de sección oblonga con diseños incisos en fajas, también podríamos incluir en este grupo una fíbula del asentamiento cacereño de Talavera la Vieja (Jiménez y González 1999: fig. 4: 3). De perfil triangular alto, presenta fajas en las que alternan diferentes motivos incisos paralelos.

La de puente asimétrico proviene del Cerro de la Muralla de Alcántara, Garrovillas, Cáceres (Esteban 1988: fig. VII,7), con brazos amorcillados y decoración de fajas compuestas por incisiones paralelas dobles que separan estrechas subfajas lisas (Fig. 3: 6). La mortaja es corta y el codo, aligerado en su sección, es consistente en relación con los brazos del puente. Este aspecto falta en los ejemplares de Agujetas y Ría de Huelva.

Por último, la fíbula de "tipo Huelva" de San Román de Hornija, Valladolid (Delibes 1978), es de brazos con sección oblonga. Las semejanzas, en este caso, se refieren al tipo de decoración desarrollada en la parte inferior de ambos brazos del puente (Fig. 3: 7) y está compuesta, como en Agujetas y posiblemente en la Ría de Huelva, por una amplia faja de finas incisiones paralelas, bien delimitadas en sus terminales. Esta pieza es la única, entre las del "tipo Huelva", que presenta este tipo de decoración, al igual que ocurre con las de la Ría de Huelva y Agujetas, entre las que denominamos lisas o "tipo Monachil".

Discrepamos con la reconstrucción de Celestino (2001: fig. 52) de una fíbula procedente de Talavera la Vieja, Cáceres, en la que consideramos forzó un asimetrismo inexistente. Su forma responde más al tipo que ya definimos como "Monachil", de codo sensiblemente centrado (Carrasco et al. 1999).

También puede entrar en el "tipo Monachil" otro ejemplar de La Muralla de Valdehuncar (Barroso y González 2007: fig. 5,11). Solo conserva el brazo derecho del puente, sin codo, con resorte y parte de la aguja, pero se describe con "puente de brazos y codo asimétricos", sin considerar la similar configuración de otra fíbula completa aparecida en este yacimiento con codo centrado. 


\subsection{Fíbula de codo "tipo Huelva" y estelas del Suroeste de la Península Ibérica}

Celestino (2001) realza el valor cronológico de las fíbulas, en relación con otros objetos grabados en las estelas, como los espejos, porque estos no son conocidos en registros arqueológicos del suroeste peninsular y las fíbulas sí. La tipología de las representadas no se asemeja a las de "tipo Huelva", y menos aún a las ad occhio. Sus paralelos estarían en la misma Extremadura, especialmente en los ejemplares de puente asimétrico de La Muralla de Alcántara y Villanueva de Pajares.

La taxonomía de Celestino (2001: 195) está, a nuestro entender, plagada de 'desviaciones' tipológicas. En síntesis, pueden encontrarse fíbulas de pivote calificadas como de antenas (Celestino, 2001: 193, fig. 46), o la representada en Torrejón el Rubio II, incluida en el "tipo Huelva". Esta última, la única de codo central con antenas, no es de "tipo Huelva", sino más tardía (Almagro Basch 1966: fig. 27). Extrañamente, Celestino alude al trabajo coordinado por Ruiz-Gálvez (1995) sobre las fíbulas del depósito de Huelva, pero los análisis de Almagro Basch son más exhaustivamente arqueológicos y sugerentes.

Este cúmulo de errores condiciona la argumentación cronológica de las estelas del Suroeste. Opinamos que un mayor conocimiento de las tipologías fibulares ayudaría a perfilar mejor el tema de la datación de las representaciones iconográficas de las estelas. Así, en las estelas extremeñas solo existen fíbulas de codo claramente descentrado y otras de arco, además de tipos más avanzados, mientras que en las estelas andaluzas no están representadas las fíbulas de codo. La que Celestino (2001: 438) adjudica al término malagueño de Almargen, y que hace años revisamos directamente en los fondos de su Ayuntamiento, no ofrece totales garantías de interpretación, aunque otros autores la documentasen (Villaseca 1993). La de la estela de Écija III tampoco sería de codo y la grabada en la de Ategua resulta muy dudosa. Estos datos deben valorarse porque, casi cien años después del descubrimiento del depósito de la Ría de Huelva, no ha aparecido en entornos andaluces del Suroeste, ni en toda la Baja Andalucía, una sola fíbula de codo. La de Valverde del Camino, conservada en una colección particular, carece de procedencia precisa y fiable. Todo ello incide en el tema de la formación del depósito onubense, su difícil adscripción a esos entornos, así como su escasa relación con los contextos de las estelas extremeñas.

\subsection{Valoraciones cronológicas y origen del "tipo Huelva" según otros autores}

Existe cierta confusión o sobreinterpretación de nuestras propuestas cronológicas, ya que nunca fechamos la fíbula "tipo Huelva" entre los siglos XIV-XII a.C. Al publicar la fíbula giennense de Cerro Alcalá (Carrasco et al. 1980), que no es del "tipo Huelva", solo pretendimos paralelizar sus motivos decorativos con la ornamentación de los brazaletes tipo Berzocana, que parecían inspirar la decoración de las fíbulas posteriores. La referencia se tomó al pie de la letra, criticándosenos (Blasco 1987) que quisiéramos emparentar cronológicamente Cerro Alcalá y Berzocana, lo que nunca pretendimos. Se obvió así la cuestión que queríamos plantear en realidad: la existencia de un modelo decorativo propio del Bronce Final en Andalucía oriental, que pudiera fecharse a partir del constatado en Berzocana. El modelo se conocía en muchos hallazgos procedentes, al parecer, de ambientes funerarios, pero que eran antiguos o superficiales y estaban inéditos. De cualquier modo, los tratamientos decorativos superficiales, similares en fíbula y brazaletes, apuntan a una larga tradición artesana perdurable en pleno Bronce Final.

Tres décadas después de la publicación de esta fíbula, Celestino tomó la referencia para modificar la supuesta cronología de F. Molina (1977) sobre las fíbulas de codo y puntualizarnos que entre los siglos XIV y XII "difícilmente podían existir estos tipos en Sicilia y menos aún en Huelva" (Celestino 2008: 114). Desde luego, nadie se preguntó si las fíbulas sicilianas, las de "tipo Huelva" y la de Cerro Alcalá, tenían algo en común.

Fechamos la fíbula del Cerro de la Miel (Carrasco et al. 1985), en origen, en los siglos XI/X a.C., sin excluir el XII (Carrasco y Pachón 2006a). Los ejemplares de la Ría de Huelva formarían parte de la evolución del tipo, pero no de sus orígenes, por lo que alguno de ellos puede datarse en el siglo $\mathrm{X}$ a.C. o en el IX, pero sin constituir prototipos. Del taller de Guadix procede una sola fíbula, no "algunas" (Celestino 2008: 114), fechada en el primer tercio del siglo IX a.C., no en el $\mathrm{X}$, propio de un momento evolutivo tardío del 
“tipo Huelva" (Carrasco et al. 2002). La fíbula de la tumba 523 de Amathus no aporta nada a la comprensión del "tipo Huelva", menos aún a su datación en el siglo X a.C. En nuestra opinión, el modelo de Celestino, tomado de Blasco (1987) y ésta, a su vez, de los estudios pioneros de Almagro Basch sobre la aparición y mezcla de tipos sículos y sirio-chipriotas en la Ría de Huelva, carece de contrastación y trasluce un arcaico y periclitado trasfondo difusionista.

Tampoco compartimos que la diferenciación de tipos fibulares, y menos aún la de su distribución peninsular, tenga escaso significado por la supuesta convivencia de todos ellos en el siglo X a.C., "en concordancia con los espejos del depósito de Lloseta" (Celestino 2008: 114).

Desanima comprobar que el actual estado de la investigación siga desconociendo la tipología de las fíbulas de codo antiguas peninsulares. Eso explica la adjudicación tipológica y cronológica que se da a la fíbula de Las Lunas. Resulta chocante su asimilación con el famoso ejemplar liso de la Ría de Huelva (Urbina y García Vuelta 2010: 189), hipotéticamente reconstruida por Almagro Basch como fíbula de puente asimétrico, como ya hemos comentado. También la asocian con la fíbula de San Román de Hornija, las de Mondim da Beira y Monte Airoso, la ad occhio de Mola d'Agrés, las fíbulas de codo "tipo Huelva" -con las que englobarían el ejemplar madrileño de Perales del Río- y, por último, con la granadina del Cerro de la Miel. Indican que atribuimos "un origen peninsular para todas las fíbulas de codo que llamamos de tipo Huelva, en cuyo esquema evolutivo los ejemplares aquí reseñados constituirían los prototipos más antiguos" (Urbina y García 2010: 189-190), lo que no coincide con nuestra posición (Carrasco y Pachón 2006a, b, c).

Urbina y García Vuelta (2010: 189) aluden al trabajo de Torres (1999), como inspiración del argumentario ya descrito sobre Las Lunas, aunque deberían referirse a una aportación posterior (Torres 2002). Hacemos responsable a este investigador de otra serie de equívocos y opiniones controvertidas. Torres incluye, en el grupo que llama Cassibile II-III, la fíbula lisa documentada en el depósito de la Ría de Huelva que nosotros adjudicamos al "tipo Monachil", un modelo sículo de la nomenclatura tradicional. Siguiendo a Almagro Basch, Ruiz Gálvez, etc., la "considera de clara procedencia siciliana y que, casi con seguridad fue importada de esta isla" (Torres 2002: 170). Indicando a continuación, que "morfológicamente se corresponde con el tipo de la fíbula de codo, aunque en este caso no presenta en el puente las típicas molduras que caracterizan el tipo Huelva, mayoritario en el depósito". La representa, siguiendo la documentación de M. Ruiz Gálvez (1995: lám. 11, n. ${ }^{\circ}$ 27), en la figura VIII.5 (Torres 2002) junto con un ejemplar del "tipo Huelva" del mismo depósito. El error es achacable al confusionismo tipológico del tratamiento fibular en la obra de Torres, al desequilibrio en su apoyo bibliográfico y, quizás, también a la equívoca representación gráfica por parte de Ruiz-Gálvez (1995) del conjunto broncíneo de la Ría de Huelva.

Para Torres (2002: 171) "la importancia de estas piezas radica en que, seguramente, son de las que derivarán las fíbulas de tipo Ría de Huelva, que tanta difusión tendrán en el Sudoeste peninsular $\mathrm{y}$, en general, en toda la fachada atlántica". El texto induce a confusión, al referirse a las fíbulas en plural, cuando solo hay una y problemática. Más recientemente insiste en que "en este depósito se ha recuperado una docena de fíbulas de codo, entre piezas completas y fragmentos que reciben su nombre de tipo Huelva" y "una siciliana de tipo Cassibile" (Torres 2008: 64). Este cómputo irreal sirve para comprobar la confusa información manejada sobre estos imperdibles antiguos y para comprender algunas aseveraciones del primer texto acotado de este autor, relativas a que del supuesto tipo Cassibile de la Ría de Huelva derivan el resto de los ejemplares de "tipo Huelva" del depósito.

La adscripción de esta fíbula lisa al tipo Cassibile, quizás se deba al supuesto asimetrismo de su puente, basado en la hipotética reconstrucción de Almagro Basch (1957: fig.1, 10), ya comentada (Fig. 4). Algo incorrecto, como que esta fíbula pueda considerarse en el origen del resto del "tipo Huelva" del depósito. En definitiva, ni por composición metálica, ni por tipología, ni cronología, esta fíbula puede estar en el origen de las de "tipo Huelva". Tampoco estas últimas, como indica Torres (2002: 171), inspirado en trabajos previos, tienen una amplia dispersión en el Sudoeste, ni en la fachada atlántica. La dispersión del registro fibular tipo Huelva coincide con el interior de la Península Ibérica (Carrasco y Pachón 2006a: fig. 1). Desconocemos el origen preciso de las fíbulas del depósito onubense, y los 
análisis de isótopos de plomo realizados hasta ahora sugieren, como procedencias probables del metal, las zonas interiores de Sierra Morena y el Valle de la Alcudia (Montero Ruiz et al. 2007). Los ejemplares portugueses, ni se localizan en asentamientos próximos a la costa, ni responden sensu stricto al "tipo Huelva". La excepción es la forma tardía de Abrigo Grande das Bocas (Carreira 1994: estampa XXXIII, 1), incluida en nuestras tablas tipológicas (Carrasco et al. 1999; Carrasco y Pachón 2006b), cuya morfometría responde en cierto modo a la de estas fíbulas españolas. Extrañamente pasó desapercibida en las investigaciones, muy en boga en los últimos años, sobre las idas y venidas de viajeros, comerciantes y metalúrgicos entre ámbitos mediterráneos, citándose en una síntesis reciente (Vilaça 2008).

Torres, apoyado en citas mal interpretadas, recorre la historia de la investigación de la fíbula "tipo Huelva". Concluye su origen en la Península Ibérica, a partir de los casos sicilianos de Pantalica II: "lo que no implica un origen oriental directo, sino la llegada de estas piezas desde el Mediterráneo central para evolucionar rápidamente de forma autónoma en la Península Ibérica" (Torres 2002: 171). Planteamiento que se apoya en un mapa incompleto de dispersión de la fíbula "tipo Huelva" (Torres 2002: fig. VIII-7), en el que mezcla tres modelos fibulares diferentes, cuyas procedencias no siempre cita.

Refleja el auténtico tipo Huelva en los hallazgos de la ría onubense, Valverde del Camino, Cerro de los Infantes, Cerro de la Miel, Cerro de los Allozos, Guadix, Talavera la Vieja, San Román de Hornija, Castro de Yecla y Burgos. El conjunto fibular es escaso para la época en que Torres publicó su trabajo. Ya se conocían (Carrasco et al. 1999) las fíbulas del Castro de la Cildad de Sabero, Casa Nueva, Abrigo Grande das Bocas, etc. Esto podría obviarse, pero no el incluir en el grupo Huelva tipos que ni lo son, como la fíbula de puente asimétrico de La Muralla; ni existen, como las del Cerro de la Mora, Peña Negra de Crevillente y El Coronil, de las que tampoco cita las referencias usadas para incluirlas en este conjunto. En especial la última, de la que Ruiz Delgado presentó en un trabajo póstumo los análisis metalográficos de la misma, pero nunca su dibujo (Ruiz Delgado et al. 1991), publicado por primera vez por nosotros (Fig. 3: 1) (Carrasco et al. 1999).
Por último, Torres, al referirse a la cronología de las fíbulas de codo, sin mayor especificación, indica que el C14 calibrado y las fechas dendrocronológicas de Europa Central apuntan a los siglos X-IX a.C., "pudiendo ya fechar algunas a finales del segundo milenio, aunque en ningún caso en una fecha tan alta, siglos XIV-XII a.C." (Torres 2002: 172). La cronología de la fíbula se remite de nuevo a la del Cerro Alcalá. Esa fecha resulta muy alta para fíbulas como la de Cerro Alcalá, pero no tanto para el "tipo Huelva", especialmente en su tramo bajo del siglo XII a.C. De todos modos, recurrir para fechar fíbulas "tipo Huelva" a un trabajo de 1980 sobre un ejemplar muy diferenciado de estas parece forzado, máxime cuando, al menos desde 1985, en múltiples trabajos hemos intentado definir su cronología con parámetros más fidedignos.

La datación por parte de Urbina y García Vuelta (2010) del "tipo Huelva" y la fíbula de Las Lunas en el siglo IX a.C., siguiendo modelos y cronologías de la fase IIB de Cassibile, puede parecer más o menos correcta. Sin embargo, la argumentación se complica, al avalar esta cronología con referencia a fíbulas tan apartadas tipológicamente como las de San Román de Hornija del siglo X a.C., Mola d'Agrés entre los siglos X-IX y "fíbulas granadinas como la del Cerro de la Miel". Para este tema no incluyen la de Perales del Río, que consideran la más próxima geográficamente a la toledana. De nuevo, confunden los tipos fibulares, extrayendo cronologías que no pueden relacionarse con la ofertada para la fíbula de Las Lunas.

De igual forma, Urbina y García Vuelta (2010: 193 ) indican que rechazamos "la procedencia siciliana de los modelos que hemos relacionado más estrechamente con la fíbula de Las Lunas liberándose de las cronologías sículas para centrarse en las peninsulares que abogan por el siglo XI a.C. como momento de comienzo del modelo, y fechan en el siglo $\mathrm{X}$ conjuntos tan conocidos como los de la Ría de Huelva o la Roça de Casal do Meio (Carrasco y Pachón 2006a: 283 ss.)". Pero, a partir de la página en que nos citan, en ningún momento nos referimos a cronologías de la Ría de Huelva, ni menos aún a Casal do Meio. Sería factible la cronología del siglo X a.C. para algunas fíbulas de "tipo Huelva" del depósito onubense, especialmente para las antiguas, y para la ad occhio portuguesa. Pero, para esta última, seguimos considerando más

Trab. Prehist., 69, N. ${ }^{\circ}$ 2, julio-diciembre 2012, pp. 310-331, ISSN: 0082-5638

doi: $10.3989 /$ tp.2012.12094 
adecuada la de inicios del siglo IX a.C. Es cierto que sí desligamos totalmente las fíbulas "tipo Huelva" de unos modelos sicilianos, que no se han localizado en Sicilia. El origen de las fíbulas "tipo Huelva", de las peninsulares ad occhio y de las "tipo Monachil", o "sículas" en terminología tradicional, nada tiene que ver con la fíbula de Las Lunas. Pero los investigadores de este depósito toledano sugieren "que las fechas que se manejan para ejemplares como el aparecido en Las Lunas, coinciden grosso modo con la fecha de C14 de finales del XI-inicios del X a.n.e." (Urbina y García 2010: 193). Como no conocemos el origen de esta cronología, ni qué ejemplares similares al de Las Lunas han sido datados por $\mathrm{C} 14$, ni si han proporcionado fechas del siglo XI, da la impresión que esta datación ha sido tomada de la ofertada hace más de veinticinco años para el ejemplar del Cerro de la Miel (Carrasco et al. 1985); que también ha sido asimilada tipológicamente al ejemplar de Las Lunas, lo que está totalmente fuera de lugar.

En nuestra opinión, sin mayor detalle, una cronología del siglo $\mathrm{X}$ a.C. para la fíbula de Las Lunas, quizás sería más ajustada: la datación absoluta obtenida sobre un fragmento de madera quemada de una cabaña próxima al depósito metálico, del $2870 \pm 50$ (Cal. BC 1 б: 1120-980, Cal. BC 2 б: 1210-910), es sugerente desde el momento en que ninguna de sus calibraciones baja del siglo X a.C. Pero ignoramos cuándo se conformó el depósito y si esta cronología corresponde con la fíbula.

\section{4. ÚLTIMAS CONSIDERACIONES Y CONCLUSIONES}

Los nuevos hallazgos de fíbulas de codo "tipo Huelva", en la Península Ibérica, constituyen una buena noticia. Hasta no hace muchos años, estas fíbulas antiguas eran muy poco conocidas. Se restringían, casi exclusivamente, a las documentadas en el depósito de la Ría de Huelva y en la Submeseta norte. Muchas de las meseteñas eran apariciones esporádicas, en paradero desconocido, pero reproducidas en publicaciones antiguas. A partir de los setenta estos antiguos imperdibles incrementan su número y dispersión regional en la Meseta, Extremadura, Portugal, en especial en Andalucía Oriental y, últimamente, en Galicia. Destaca su ausencia en las áreas levantina, catalana y costera andaluza, es decir, de toda la costa mediterránea. Podríamos considerar esa casuística, a priori y sin otras connotaciones, como algo "exclusivamente accidental" (Fig. 5), a la espera de que posteriores hallazgos amplíen la dispersión.

La investigación de ese mayor volumen conocido de fíbulas no ha avanzado como hubiese sido necesario o predecible, sino merced a saltos de supuestos imposibles, desconocimiento de los registros y valoraciones más o menos interesadas. Aún nos quedamos, trascurridos más de cincuenta años, con las aportaciones de los trabajos de Almagro Basch. Se puede estar o no de acuerdo con ellas, pero el alto horizonte de conocimiento y la precisa documentación que expusieron, hoy es cada vez más difícil de encontrar.

Las conclusiones que mostramos aquí a partir de las nuevas fíbulas, especialmente de las referidas al "tipo Huelva" y de la lisa de las Agujetas, no modifican lo que venimos exponiendo desde 1985. Sí aportan, en cambio, un más detallado conocimiento de su tipología y una mejor comprensión de su distribución regional. Un rápido y sintético recorrido sobre ellas apoyará algunas puntualizaciones, especialmente relacionadas con sus orígenes y cronología.

Almagro Basch (1940a), en sus estudios pioneros sobre las fíbulas de codo de la Península Ibérica, las consideraba los únicos objetos del depósito de la Ría de Huelva que reflejaban relaciones directas con el Mediterráneo Central, haciéndolas derivar, ya más evolucionadas por su decoración, de las formas sículas tardías de Cassibile, con una fecha no anterior al 750 a.C. Opinaba que "los tipos sicilianos han hecho nacer, desde luego, los modelos españoles, del que es el más antiguo ejemplar el de Huelva, pero no es el único, y de ninguna manera de la misma época que sus precedentes sicilianos" (Almagro Basch 1940b: 3). En un posterior trabajo, insistía en datar la totalidad del depósito onubense en el 750 a.C. por la aparición de estas fíbulas (Almagro Basch 1957). Pero, cada vez más, fue sustituyendo los paralelos del Mediterráneo Central por los de Chipre y Palestina, para justificar la presencia de las fíbulas "tipo Huelva" en la Península Ibérica, en relación con el comercio fenicio-chipriota. Primero, consideró el tipo de fíbula de Kourion como precedente y origen directo de la de Huelva (Almagro Basch 1957). Posteriormente, la interpretará como una variante provincial, derivada del tipo Kourion-Megiddo, incluyendo otros pa- 


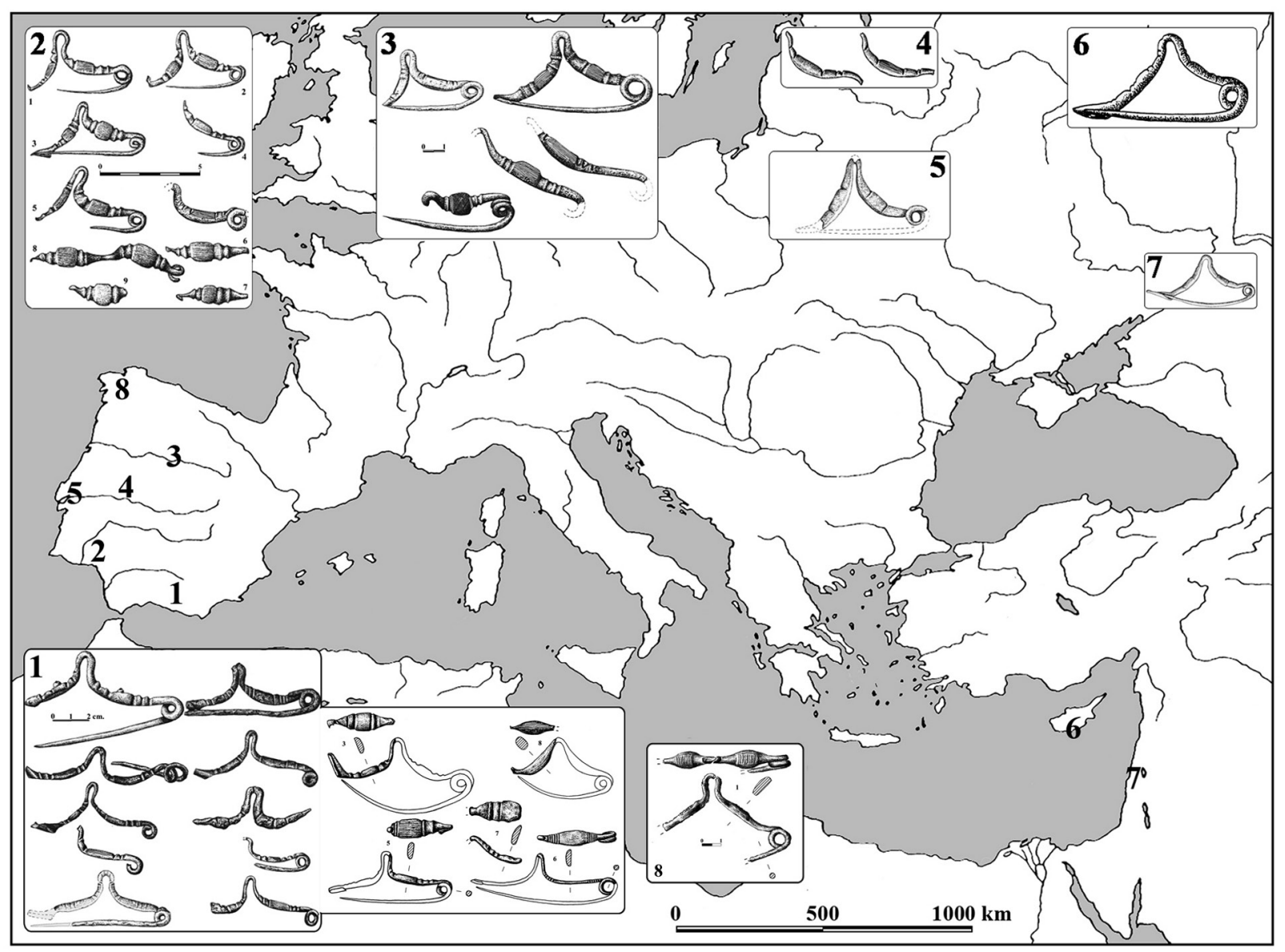

Fig. 5. Mapa de dispersión de las fíbulas "tipo Huelva”, más la lisa de Las Agujetas. Actualización 2011.

ralelos cronológicos de más difícil filiación como las "de arco triangular con botón en el vértice del ángulo, tipo Tamasos, Lindos, Egina...” (Almagro 1957: 36). Sus apreciaciones fueron coherentes con su época, especialmente las referidas -con matizaciones- a los paralelos orientales. Sus paralelos sículos, en nuestra opinión, no fueron tan acertados, al referirse a su reconstrucción hipotética del ejemplar liso del depósito de la Ría de Huelva, al que, siempre desde nuestra experiencia, se le atribuyó un puente totalmente asimétrico, como a algunas del "tipo Huelva". La investigación oficial aceptó su cronología de mediados del siglo VIII a.C. para ese depósito durante más de cuarenta años. Solo en los últimos años ha sido elevada de forma paulatina y con argumentos, en ocasiones, poco más firmes que los suyos.

En resumen, estas fíbulas se fecharon a mediados del siglo VIII a.C., como productos exó- genos o derivados de ellos; en última instancia llegados, primero, desde el área insular italiana y, después, desde Chipre y Palestina. Más tarde, Hencken (1956, 1957), Birminghan (1963), Bernabó Brea (1958, 1964-65), Guzzo (1969), entre otros (Carrasco y Pachón, 2006a, 2006b, 2006c), admitieron o matizaron las hipótesis de Almagro, centrándose más que nada en la búsqueda de paralelos en el Mediterráneo Central u Oriental y datándolas entre los siglos IX, VIII e incluso X a.C., casi siempre bajo la óptica de modelos difusionistas y paralelos descontextualizados.

A partir de los años 1970, la investigación sobre el tema fibular sufre un cambio brusco. Entran en escena las dataciones radiocarbónicas, cuya interpretación ha dado lugar, como hemos indicado en alguna ocasión (Carrasco y Pachón, 2006a), a la etapa de calibraciones y re-calibraciones y, más recientemente, a una fase que de- 
nominamos de las "maderas viejas y jóvenes". La publicación de seis fechas C14, obtenidas a partir de madera extraída de los regatones de algunas lanzas del depósito onubense (Almagro-Gorbea 1978), sitúan la nueva cronología de las fíbulas entre 880 y 850 a.C.; es decir, en el siglo IX a.C. Como esta cronología parecía coincidir con los presupuestos de la investigación de la época, se asignó, sucesivamente, a los posteriores hallazgos broncíneos en la Península Ibérica, que guardaban alguna similitud con los metales recuperados en la Ría de Huelva. Nunca llegó a plantearse, si todos se enmarcaban en esa cronología, si se correspondía con la fecha del "hundimiento del barco", o si encajaba mejor con los objetos más tardíos del depósito.

Poco después, y oportunamente, FernándezMiranda y Ruiz-Gálvez (1980) intentaron reordenar el contexto cultural del depósito onubense con estas dataciones absolutas, pero su lectura del problema fue incorrecta. Se basaron, especialmente, en paralelos de fíbulas francesas que poco, o nada, compartían con las de "tipo Huelva" y cuyas fechas absolutas provenían de la extrapolación de otros referentes y alejados lugares de hábitat. En apoyo de los inicios del siglo IX, recurrieron a la fecha corta del 870 a.C., obtenida para una fíbula "tipo Huelva" en San Román de Hornija (Delibes 1981).

En 1985 tuvimos la oportunidad de contextualizar en el Cerro de la Miel una fíbula de codo "tipo Huelva", junto a una extraordinaria espada de lengua de carpa (Carrasco et al. 1985). Posiblemente, constituye el mejor conjunto en su especie; pero, por desgracia, la datación por primera vez de estos elementos broncíneos, entre el siglo XI y principios del X a.C., rompía con los esquemas cronológicos de la época. El mayor problema fue la desviación típica muy alta de la datación absoluta por C14 convencional, obtenida por el laboratorio de la Universidad de Granada. Sin ella esa fecha habría sobrepasado el siglo XI como indicaba el conjunto cerámico acompañante, a medio camino entre el Bronce Tardío y el Bronce Final Antiguo. Pese a las críticas de los primeros momentos, esta fecha antigua se ha venido asumiendo e imponiendo.

Sin embargo, Ruiz-Gálvez, especialmente en sus investigaciones relativas al depósito onubense (Ruiz-Gálvez 1995), -a nuestro entender- confundió nuestras disquisiciones tipológicas-cronológicas sobre la fíbula y espada del Cerro de la
Miel. Esta investigadora inicia la verdadera fase que denominamos de "calibraciones y re-calibraciones". Justifica la cronología del siglo XI a.C. a partir de una visión, ya criticada en detalle (Carrasco y Pachón 2006c), que combina calibraciones realizadas sobre dataciones de la Ría de Huelva, San Román y Cerro de la Miel, y comparaciones entre una globalidad de fíbulas de tipología y ambientes muy diversos. Resaltaremos aquí que Ruiz Gálvez ofreció una insuficiente versión del estudio de Almagro Basch, realizado hace más de cincuenta años. Pero las investigaciones posteriores de Celestino y Torres muestran que Ruiz-Gálvez ha creado escuela en el mundo de las fíbulas antiguas peninsulares, aunque con resultados discutibles.

Otras investigaciones han ofrecido visiones bastante más coherentes. Coincidimos en parte con las posibilidades que abre Mederos (1996), al fechar alguna de las fíbulas "tipo Huelva" en los siglos XII/XI a.C., así como que se extendieran durante los siglos X-IX a.C. con los contactos pre-coloniales desde la Península Ibérica hasta ciertos ambientes del Mediterráneo Oriental. No estamos muy de acuerdo con el ejemplo particular de la fíbula de la tumba 523 de la necrópolis chipriota de Amathus, aducido por Mederos (Carrasco y Pachón 2006a y c), pero ello no quita relevancia a la opinión del autor.

Las décadas de 1990 y 2000 están marcadas por el conocimiento de nuevos hallazgos fibulares, los trabajos comentados de Celestino (2001) y Torres (2002) y nuestros propios análisis sobre aspectos concretos de las fíbulas "tipo Huelva" (Carrasco y Pachón 2006a, b, c), como el tipo fibular y su secuencia evolutiva, su cronología y la problemática sobre el origen oriental de estos imperdibles. Tras estos estudios, importantes para la comprensión global de este tipo de fíbulas, entraríamos en lo que denominamos etapa de las "maderas viejas y jóvenes", por la valoración que se hace de las muestras empleadas para la datación por $\mathrm{C} 14$, iniciada con la reciente aportación de Torres (2008) y de la que hemos tratado aspectos puntuales.

De las reflexiones y puntualizaciones previas extraeríamos una serie de conclusiones generales: es evidente la ayuda de las nuevas fíbulas de codo "tipo Huelva" para definir mejor el tipo y su distribución espacial; cuantos más ejemplares se conozcan, más consistencia tendrá la forma y posterior evolución del tipo. El registro actual de 
estas fíbulas sensu stricto en la Península Ibérica estaría compuesto por treinta y un ejemplares: diez se localizaron en la provincia de Huelva (nueve en el depósito de la Ría de Huelva y una de la colección particular de Valverde del Camino), doce en la provincia de Granada, cinco en la Meseta, dos en Extremadura, una en Galicia y otra en Portugal. Fuera de la Península Ibérica, el único ejemplar fiel a los parámetros que hemos expuesto para el "tipo Huelva" se localiza en la necrópolis israelita de Achziv (Mazar 2004: fig. 28.1), aunque también incluimos en el mapa de dispersión (Fig. 5) la procedente de la sepultura 523 de Amathus, Chipre, con menos afinidades. Es decir, que la fíbula "tipo Huelva" está representada por 33 ejemplares, ninguno salido de un mismo molde, lo que le proporciona suficiente entidad y personalidad propia. Su amplia dispersión en la Península Ibérica, siendo prácticamente nula fuera de ella, permite considerarla una forma original peninsular sin claras deudas exógenas. Y si las hubiese, no serían - precisamentepropias de ambientes sículos.

$\mathrm{Su}$ distribución, contextualización y características morfométricas dan prioridad cronológica a algunos ambientes interiores de la Alta Andalucía. No se documenta en las áreas costeras, ya que desconocemos de dónde procede, en realidad, el conjunto del depósito de la Ría de Huelva. Los resultados de procedencia del metal con isótopos de plomo, de algunas de sus espadas y lanzas (Montero et al. 2007), apuntan a otros posibles ámbitos andaluces e incluso meseteños o extremeños (1). La fíbula "tipo Huelva" pudo aparecer en el siglo XII a.C., pero con unas pervivencias durante el IX, llegando, incluso, hasta principios del VIII a.C. Durante sus cuatro o cinco siglos de vigencia, el tipo pudo evolucionar, como hemos propuesto, dando lugar a formas similares pero no idénticas. Los ejemplares de El Coronil, Mondim da Beira, etc. podrían derivar de la forma original, a tenor de sus decoraciones con fajas incisas en los brazos, que recuerdan las del "tipo

(1) Recientemente se han analizado por isótopos cuatro botones y tres fíbulas de codo del depósito, dentro del proyecto bilateral CSIC (2010RU0086), Fundación Presidente de Rusia para la Investigación Fundamental (Proyecto RFBR n. ${ }^{\circ}$ 11-0693979): Provincias metalúrgicas Euroasiáticas y Europeas del II milenio a.n.e.: investigación de sus interacciones a partir de métodos científico-naturales. Los resultados confirman, al igual que los análisis previos, una procedencia del metal fuera del área onubense.
Huelva", pero sin los resaltes y desarrollos de las fajas que estas tienen en origen, por lo que no pueden considerarse como tales, aunque hayamos tenido alguna opinión dudosa al respecto.

Fuera de la Península Ibérica, la serie chipriota, bien estudiada por Buchholz (1985) y mejor documentada por Giesen (2001), es la más parecida. El ejemplar de Kourion podría haber inspirado el "tipo Huelva". El resto de ejemplares son más evolucionados, a juzgar por su morfometría, tipología e incluso cronología. Las fíbulas orientales, especialmente chipriotas, incluida la conocida de la tumba 523 de Amathus, al igual que las de las tumbas 229, 243 y 13, guardan evidentes similitudes con las occidentales, pero no proceden de talleres hispanos y no justificarían contactos "pre-coloniales". En el área palestina israelí, la fíbula de Samaria-Sebarte y especialmente la de Megiddo VA, propuesta por Torres (2008: 83), para justificar intercambios con el Mediterráneo Oriental, en nuestra opinión tampoco procederían de la Península Ibérica. La única fíbula, como hemos indicado, que puede encajar en las pautas de desarrollo y taxonomía tipológica de las fíbulas ibéricas es la israelita de Achziv, en un momento (siglo $\mathrm{X}$ a.C.) en que ya estaba conformado el "tipo Huelva" en la Península (Carrasco y Pachón 2006a). Es factible justificar su presencia en territorio israelí por los intercambios comerciales e influencias mutuas que debieron existir precozmente entre ámbitos del Mediterráneo Oriental y la Península Ibérica, aunque todavía no seamos capaces de responder la cuestión de si se exportó la fíbula en sí o fue la idea del modelo.

La fíbula lisa del Cerro de las Agujetas, idéntica a la localizada por Almagro Basch en el depósito de la Ría de Huelva, poco o nada tiene que ver con ambientes sículos y bajo ningún supuesto constituye el origen paradigmático de las del tipo Huelva.

\section{BIBLIOGRAFÍA}

Almagro Basch, M. 1940a: "El hallazgo de la Ría de Huelva y el final de la Edad del Bronce en el Occidente de Europa". Ampurias 2: 85-143.

Almagro Basch, M. 1940b: "La cronología de las fíbulas de codo". Saitabi III: 1-5.

Almagro Basch, M. 1957: "La fíbula de codo de la Ría de Huelva. Su origen y cronología". Cuadernos de la Escuela Española de Roma IX: 7-45. 
Almagro Basch, M. 1957-58: "A propósito de la fecha de las fíbulas de Huelva". Ampurias XIX: 198207.

Almagro Basch, M. 1958: Depósito de la Ría de Huelva. Inventaria Arqueológica. España, 1-4: E. 1, Madrid.

Almagro Basch, M. 1966: Las estelas decoradas del Suroeste Peninsular. Bibliotheca Praheistorica Hispana VIII, CSIC, Madrid.

Almagro Gorbea, M. 1977: El Bronce Final y el Período Orientalizante en Extremadura. Bibliotheca Praehistorica Hispana XVI, CSIC, Madrid.

Almagro Gorbea, M. 1978: "Las dataciones para el Bronce Final y la Edad del Hierro y su problemática". En M. Almagro y M. Fernández (eds.): C-14 y Prehistoria de la Península Ibérica. Fundación March. Madrid: 101-109.

Almagro Gorbea, M. y Fernández Miranda, M. 1978: C-14 y Prehistoria de la Península Ibérica. Fundación Juan March, Serie Universitaria, 77, Madrid.

Álvarez, Y. y López, L. F. 2000: "La secuencia cultural del asentamiento de Laias: Evolución espacial y funcional del poblado". $3^{\text {er }}$ Congresso de Arqueología Peninsular. Proto-História da Península Ibérica, Porto, vol. 5: 524-532.

Barroso, R. y González, A. 2007: “Datos para la definición del Bronce Final en la zona suroccidental de la Meseta. Los Yacimientos de la Comarca del Campo Arañuelo (Cáceres)". Revista de Estudios Extremeños 63(1): 11-36.

Bernabó Brea, L. 1958: Alt-Sizilien. Entwicklung griech. Kolonisation (Übers. aus d. Engl). Koln.

Bernabó Brea, L. 1964-65: "Leggenda e archeologia nella protoistoria siciliana. Atti Congresso Internazionale di Studi sulla Sicilia antica". Kokalos, XXI: 1-33.

Birmingham, J. 1963: "The development of the fibula in Cyprus and the Levant". Palestine Exploration Quarterly: 80-112.

Blasco Bosqued, M. ${ }^{\text {a }}$ C. 1987: "Un ejemplar de fíbula de codo 'ad occhio' en el Valle del Manzanares". Boletín de la Asociación Española de Amigos de la Arqueología 23: 18-28.

Brandherm, D. 2007: Las espadas del Bronce Final en la Península Ibérica y Baleares. Prähistorische Bronzefunde IV.16. Stuttgart.

Buchholz, H. G. 1985: "Ein kyprischer Fibeltypus und seine auswartige Verbrei tung". Cyprus Between the the Orient and the Occident. Acts of the Internacional Archaological Symposium. Nicosia: 223-245.

Burgess, C. y O'Connor, B. 2008: "Iberia, the Atlantic Bronze age and the Mediterranean". Contacto cultural entre el Mediterráneo y el Atlántico (siglos XII-VIII ane). La precolonización a debate. Serie Arqueológica 11, CSIC, Escuela Española de Historia y Arqueología en Roma. Madrid: 41-58.
Carrasco, J. y Pachón, J. A. 2001: "Fíbula de codo tipo Huelva en el entorno norte de la Vega de Granada". Spal 10: 235-248.

Carrasco, J. y Pachón, J. A. 2002: "Fíbulas de codo en las altiplanicies granadinas: dos nuevos hallazgos en la comarca de Guadix". Tabona 11: 169-188.

Carrasco, J. y Pachón, J. A. 2004: "Fíbulas de codo de tipo Huelva en la Provincia de Granada. Revista del Centro de Estudios Históricos de Granada y su Reino 16:13-69.

Carrasco, J. y Pachón, J.A. 2006a: "Sobre la cronología de las fíbulas de codo tipo Huelva". Archivo de Prehistoria Levantina XXVI: 245-292.

Carrasco, J. y Pachón, J. A. 2006b: "La fíbula de codo tipo Huelva. Una aproximación a su tipología". Complutum 17: 103-119.

Carrasco, J. y Pachón, J. A. 2006c: “Algunas cuestiones sobre el origen oriental de la fíbula de codo tipo Huelva". Tabona 14: 63-92.

Carrasco, J.; Pachón, J. A.; Adroher, A. y López, A. 2002: "Taller metalúrgico de fines del bronce en Guadix (Granada): contribución a la contextualización de las fíbulas de codo tipo Huelva en Andalucía Oriental". Florentia Iliberritana 13: 357-385.

Carrasco, J.; Pachón, J. A.; Esquivel, J. A. y Aranda, G. 1999: "Clasificación secuencial tecno-tipológica de las fíbulas de codo de la Península Ibérica". Complutum 10: 123-142.

Carrasco, J.; Pachón, J. A.; Pastor, J. A. y Lara, I. 1980: "Hallazgos del Bronce Final en la provincia de Jaén. La necrópolis de Cerro Alcalá, Torres (Jaén)". Cuadernos de Prehistoria y Arqueología de la Universidad de Granada 5: 221-36.

Carrasco, J.; Pachón, J. A. y Pastor, M. 1985: "Nuevos hallazgos en el conjunto arqueológico del Cerro de la Mora. La espada de lengua de carpa y la fíbula de codo del Cerro de la Miel (Moraleda de Zafayona, Granada)". Cuadernos de Prehistoria y Arqueología de la Universidad de Granada 10: 265-333.

Carreira, J. R. 1994: “A Pré-História recente do Abrigo Grande das Bocas (Rio Mayor)". TAEAM, 2, Lisboa: 47-144.

Celis, J. 1998-1999: "Una fíbula de codo en las estribaciones de la cordillera cantábrica: La Cildad, Sabero, León". Lancia 3: 287-296.

Celestino, S. 2001: Estelas de guerreros y estelas diademadas. La precolonización y formación del mundo tartésico. Bellaterra Arqueología. Barcelona.

Celestino, S. 2008: "La precolonización a través de los símbolos." En S. Celestino, N. Rafel, y L. Armada (eds.): Contacto cultural entre el mediterráneo y el atlántico (siglos XII-VIII a.n.e). La precolonización a debate. Serie Arqueológica 11, Escuela Española de Historia y Arqueología en Roma, CSIC. Madrid: 107-119.

Contreras, F.; Carrión, F. y Jabaloy, E. 1983: “Un horno de alfarero protohistórico en el Cerro de los 
Infantes (Pinos Puente, Granada)". XVI Congreso de Arqueología Nacional: 533-538. Zaragoza.

Cruz, P. J. y Quintana, J. 1999: "Reflexiones sobre la metalurgia de Bioes-Vénat en el interior de la Submeseta norte y su relación con los contextos del tránsito del bronce al hierro". En R. Balbín y P. Bueno (eds.): Actas del II Congreso de Arqueología Peninsular III Primer Milenio y Metodología: 161-170. Zamora.

Delibes, G. 1978: "Una inhumación triple de facies Cogotas I en San Román de Hornija (Valladolid)". Trabajos de Prehistoria 35: 225-250.

Delibes, G. 1981: "Una interesante fíbula del Bronce Final del Cerro del Berrueco (Salamanca)". Guimarâes XVI: 172-182.

Esteban Ortega, J. 1988: "El yacimiento protohistórico de 'El Cerro de la Muralla' (Alcántara-Cáceres): Hallazgos metálicos". Actas del I Congreso Peninsular de Historia Antigua 1: 265-294. Santiago de Compostela.

Fernández Miranda, M. y Ruiz-Gálvez, M. 1980: “El depósito de la Ría de Huelva y su contexto Cultural". Oskitania 1: 65-80.

Giesen, K. 2001: Zyprische Fibeln. Typologie und Chronologie. Paul Aströms Förlag, Sweden.

Gil-Mascarell, M. y Peña, J. L. 1989: "La fíbula ad occhio del yacimiento de la Mola d'Agrés". Saguntum 22: 129-144.

Giumilia-Mair, A.; Albanese, R. M. y Lo Schiavo, F. 2010: "The Metallurgy of the Sicilian Final Bronze Age/Early Iron Age necropolis of Madonna del Piano (Catania, Sicily)". Trabajos de Prehistoria 67(2): 469-488.

González-Salas, S. 1936-1940: "Hallazgos arqueológicos en el alto de Yecla, en Santo Domingo de Silos (Burgos)". Actas y Memorias de la Sociedad Española de Antropología, Etnografía y Prehistoria XV: 103-123. Madrid.

González-Salas, A. 1945: El castro de Yecla en Santo Domingo de Silos (Burgos). IMCGEA 7, Madrid.

Guzzo, P.G. 1969: "Considerazioni sulle fibule del ripostiglio da1 Ria de Huelva". Rivista di Scienze Preistoriche XXIV(2): 299-309.

Hencken, H. 1956: "Carp's Tongue Sworfs in Spain, France and Italy". Zephyrus VII: 125-178.

Hencken, H. 1957: "The Fibulae of Huelva". Proceedings of the Prehistoric Society 22: 213-215.

Jiménez, J. y González. A. 1999: "Referencias culturales en la definición del Bronce Final y la Primera Edad del Hierro de la Cuenca del Tajo: el yacimiento de Talavera la Vieja, Cáceres". II Congreso de Arqueología Peninsular III. Primer Milenio y Metodología: 181-190. Madrid.

Kalb, Ph. 1978: "Senhora da Guia, Baiôes. Die Ausgrabung 1977 auf einer hohensiedeung der Atlantischen Bronzezeit in Portugal". Madrider Mitteilungen 19: 112-138.
Maluquer, J. 1958: "Excavaciones arqueológicas en el Cerro del Berrueco (Salamanca)". Acta Salmanticensia XVI(1): 86-238.

Mazar, E. 2004: The Phoenician family tomb $n .1$ at the Northern cemetery of Achziv (10th- $6^{\text {th }}$ centuries $B C E)$. Sam Turner expedition. Final report of the excavations. Cuadernos de Arqueología Mediterránea 10. Barcelona.

Mederos, A. 1996: "La conexión levantino-chipriota. Indicios de comercio atlántico con el Mediterráneo Oriental durante el Bronce Final (1150-950 AC)". Trabajos de Prehistoria 53 (2): 95-115.

Mederos, A. 2008: "Las espadas de tipo Huelva y los inicios de la presencia fenicia en occidente durante el bronce final IIC-IIIA (1150-950 A.C.)". Cuadernos de Prehistoria y Arqueología de la Universidad Autónoma de Madrid 34: 41-75.

Mendoza, A.; Molina, F.; Arteaga, O. y Aguayo, P. 1981: "Cerro de los Infantes (P. Puente, Provinz Granada). Ein Beitrag zur Bronze und Eisenzeit in Oberandalusien". Madrider Mitteilungen 22: 171-210.

Molina, F. 1977: La cultura del Bronce Final en el Sudeste de la Península Ibérica. Resúmenes de Tesis Doctorales de la Universidad de Granada, 178, Granada.

Montero Ruiz, I.; Hunt Ortiz, M. y Santos Zalduegui, J. F. 2007: "El depósito de la Ría de Huelva: procedencia del metal a través de los resultados de análisis de Isótopos de Plomo". En J. Celis, G. Delibes de Castro, J. Fernández Manzano y L. Grau Lobo (eds.): El hallazgo leonés de Valdevimbre y los depósitos del Bronce Final Atlántico en la Península Ibérica. Estudios y Catálogos 17, Museo de León: 194-209. .

Pachón, J. A. y Carrasco, J. 2009: "Las espuelas de jinetes ibéricas en Andalucía Oriental. El ejemplar del Cerro de las Agujetas, Pinos Puente (Granada)". Revista del Centro de Estudios Históricos de Granada y su Reino 21: 21-48.

Pachón, J. A. y Carrasco, J. 2010: "Espuela de bronce en el Cerro de las Agujetas de Pinos Puente, Granada. Un vestigio artístico de la toréutica aplicada a la implementa de los caballeros en el mundo ibérico". Antiquitas 22: 57-75.

Pachón, J. A.; Carrasco, J. y Pastor, M. 1979: "Protohistoria de la Cuenca Alta del Genil". Cuadernos de Prehistoria de la Universidad de Granada 4: 295-340.

Pastor Muñoz, M. 2002: Corpus de Inscripciones Latinas de Andalucía IV: Granada. Consejería de Cultura, Dirección General de Bienes Culturales. Sevilla.

Peinado Santaella, R. 1998: De Ilurco a Pinos Puente. Poblamiento, economía y sociedad de un pueblo de la Vega de Granada. Diputación de Granada. Granada.

Quintana, J. y Cruz, P. J. 1996: "Del Bronce al Hierro en el centro de la Submeseta Norte (Consideraciones desde el Inventario Arqueológico de Vallado- 
lid)". Boletín del Seminario de estudios de Arte y Arqueología LXII: 9-78.

Rodríguez Marcos, J. A. 2009: Estudio secuencial de la Edad del Bronce en la ribera del Duero (provincia de Valladolid). Arqueología en Castilla y León 7, Junta de Castilla y León. Valladolid.

Ruiz Delgado, M. M. 1989: Fíbulas protohistóricas en el sur de la Península Ibérica. Publicaciones de la Universidad de Sevilla. Sevilla.

Ruiz Delgado, M. M.; Respaldiza, M. A. y Barranco, F. 1991: "Análisis elemental de bronces arqueológicos por DRX y PIXE”. Internacional Conference of Prehistory. British Archaelogical Reports, Internacional Series 573, Archaepress. Oxford: 139-163.

Ruiz-Gálvez, M. 1995: Ritos de paso y puntos de paso. La Ría de Huelva en el mundo del Bronce Final Europeo. Complutum Extra 5, Universidad Complutense. Madrid.

Schüle, W. 1969: Die Meseta-Kulturen der Iberischen Halbinsel. Mediterrane und eurasische Elemente in früheisenzeitlichen Kulturen Südwesteneuropas. Madrider Forschungen 3, Walter de Gruyter. Berlin. Senna-Martinez, J. C. de 1995: "O Povoado do Cabeço do Castro de S. Româo”. En I. Silva (coord.): $A$ Idade do Bronze en Portugal. Discursos do Poder. Museu Nacional de Arqueologia. Lisboa: 61-67.

Spindler, K. 1973: "Der spätbronzezeitliche Kuppelbau von der Roca do Casal do Meio in Portugal". Madrider Mitteilungen 14: 60-108.

Storch de Gracia, J. J. 1989: La fibula en la Hispania Antigua: las fibulas protohistóricas del suroeste peninsular. Colección Tesis Doctorales 39/89, Universidad Complutense. Madrid.

Torres, M. 1999: Sociedad y mundo funerario en Tartessos. Real Academia de la Historia. Madrid.

Torres, M. 2002: Tartessos. Real Academia de la Historia. Madrid.

Torres, M. 2008: 'Los 'tiempos' de la precolonización”. En S. Celestino, N. Rafel y L. Armada (eds.): Contacto cultural entre el mediterráneo y el atlántico (siglos XII-VIII ane). La precolonización a debate. Serie Arqueológica 11, Escuela Española de Historia y Arqueología en Roma, CSIC Madrid: 59-91.

Turco, M. ${ }^{a}$ G. 2000: La necrópolis di Cassibile. Cahiers du Centre Bérard XXI. Nápoles.

Urbina Martínez, D. y García Vuelta, O. 2010: “Las Lunas, Yuncler (Toledo). Un depósito de materiales metálicos del Bronce Final en la Submeseta Sur de la Península Ibérica". Trabajos de Prehistoria 67(1): 175-196.

Vilaça, R. 2008: "Reflexões em torno da 'presença mediterrânea' no centro do territorio portugués, na charneira do Bronze para o Ferro". En S. Celestino, N. Rafel y L. Armada (eds.): Contacto cultural entre el Mediterráneo y el Atlántico (siglos XII-VIII ane). La precolonización a debate. Serie Arqueológica 11, Escuela Española de Historia y Arqueología en Roma, CSIC Madrid: 371-400.

Villaseca Díaz, F. 1993: "La estela decorada y la espada de lengua de carpa del Bronce Final de Almargen-Málaga". Baetica 15: 217-226. 